IZA DP No. 4309

Cherry-Picking in Labor Market with Imperfect Information

Shuaizhang Feng

Bingyong Zheng

July 2009 


\title{
Cherry-Picking in Labor Market with Imperfect Information
}

\author{
Shuaizhang Feng \\ Princeton University \\ and IZA \\ Bingyong Zheng \\ Shanghai University of Finance and Economics
}

\author{
Discussion Paper No. 4309 \\ July 2009
}

IZA

P.O. Box 7240

53072 Bonn

Germany

Phone: +49-228-3894-0

Fax: +49-228-3894-180

E-mail: iza@iza.org

\begin{abstract}
Any opinions expressed here are those of the author(s) and not those of IZA. Research published in this series may include views on policy, but the institute itself takes no institutional policy positions.

The Institute for the Study of Labor (IZA) in Bonn is a local and virtual international research center and a place of communication between science, politics and business. IZA is an independent nonprofit organization supported by Deutsche Post Foundation. The center is associated with the University of Bonn and offers a stimulating research environment through its international network, workshops and conferences, data service, project support, research visits and doctoral program. IZA engages in (i) original and internationally competitive research in all fields of labor economics, (ii) development of policy concepts, and (iii) dissemination of research results and concepts to the interested public.
\end{abstract}

IZA Discussion Papers often represent preliminary work and are circulated to encourage discussion. Citation of such a paper should account for its provisional character. A revised version may be available directly from the author. 


\section{ABSTRACT}

\section{Cherry-Picking in Labor Market with Imperfect Information*}

We study a competitive labor market with imperfect information. In our basic model, the labor market consists of heterogeneous workers and ex ante identical firms who have only imperfect private information about workers' productivities. Firms compete by posting wages in order to cherry-pick more productive workers from the applicant pool. The model predicts many important empirical regularities, including non-degenerated firm size distribution, persistent wage dispersion, and employer size-wage premium. We also consider extensions of the model where firms differ in either productivity or information about worker types, both generating assortative matching with a positive but imperfect correlation of worker and firm types. The main insight of this paper is that identical workers can get different wages depending on productivities of their coworkers in a competitive market with informational frictions. Our model also sheds light on inter-industry wage differential and sorting between industry and worker characteristics.

\section{JEL Classification: D83, J31}

Keywords: imperfect information, cherry-picking, wage dispersion, size-wage premium, inter-industry wage differential

Corresponding author:

Shuaizhang Feng

411A Robertson Hall

Woodrow Wilson School

Princeton University

Princeton, NJ 08544

USA

E-mail: shuaizha@princeton.edu

\footnotetext{
* We would like to thank Melvyn Coles, Hank Farber, Hanming Fang, Peter Gottschalk, Adam Hersh, Lars Lefgren, Alan Krueger, Andrew Marder, David McAdams, Bruce Meyer, Jim Smith, Wing Suen, Cheng Wang, and Tao Zhu for suggestions and comments. We also thank seminar participants at Princeton University, the 14th annual meetings of the Society of Labor Economists in Boston, and University of Essex. All remaining errors are our own.
} 


\section{Introduction}

There exists a voluminous empirical literature about wage dispersion, particularly in the forms of employer size-wage premium and inter-industry wage differential. Researchers find that large firms and certain industries pay more to observationally equivalent workers. In addition, large firms and firms in high-wage industries are also on average more productive, hire better workers, and make more profits. ${ }^{1}$

These empirical findings are quite robust over time and across different types of labor markets, yet hard to be rationalized. In a perfect competitive world, wages are not expected to be correlated with firm characteristics such as size of its workforce and industry affiliation. Among all proposed explanations, two types of models have considered specific labor market frictions which lead to equilibrium wage dispersion. ${ }^{2}$ In search models, workers only know the distribution of wage offers, and thus conduct random searches. Because workers are homogeneous, search models typically cannot predict the sorting of firms and workers (Burdett and Mortensen 1998). Alternatively, matching models consider interactions between heterogeneous workers and firms in an environment with coordination friction, and generate both wage dispersion and sorting (Shimer 2005).

This paper provides a different explanation to wage dispersion and sorting based on imperfect information about worker productivity. Our basic intuition dates back at least to Alfred Marshall who "recognized that workers were frequently not paid on the basis of tasks performed. One of the reasons for this is the inability to observe the tasks perfectly - either the inputs or outputs." (Stiglitz 2000). Despite employee signaling and employer screening (see e.g., Spence 1973 and Stiglitz 1975, and Guasch and Weiss 1981), it is reasonable to assume that firms do not know fully the

\footnotetext{
${ }^{1}$ For studies on employer size-wage premium, see Brown and Medoff (1989), Oi and Idson (1999), and Troske (1999). For studies on inter-industry wage differential, see Krueger and Summers (1988) and Gibbons and Katz (1992). For more recent studies based on linked employer-employee data, see Abowd et al. (1999).

${ }^{2}$ For theories examined and rejected, see Brown and Medoff (1989) for size-wage premium and Krueger and Summers (1988) and Gibbons and Katz (1992) for inter-industry wage differential.
} 
productive capacities of workers and have to make decisions under uncertainty. ${ }^{3}$

Our main contribution in this paper is to show that imperfect information leads to equilibrium wage dispersion in a competitive market. Furthermore, there exists sizewage premium and assortative matching between workers and firms. Our emphasis on informational friction in labor market can be illustrated by considering a specific labor market - the U.S. academic market for junior economists, where qualities of job candidates seem to be a primary concern for employers. Meanwhile, search and coordination frictions seem minimal, as job candidates have a quite good understanding of potential offers they might get from different institutions, and can send large number of applications at nominal cost.

In the basic model, we study a one period job market with infinite number of firms that are ex ante identical, and a continuum of workers who are either of high productivity type or of low productivity type. Firms only have limited private information about workers' type. The job market is characterized by a sequential wage posting game, consisting of many rounds in which firms compete by posting wage offers for the right to hire workers. In equilibrium, firms take turns to cherry-pick workers that they think are of high productive capabilities. Thus, firms hire workers of different expected productivities at different wages. Firms that hire in earlier rounds pay higher wages and draw disproportionately more high type workers.

Wage dispersion exists in equilibrium as workers of the same type are paid differently in different firms. Those who are 'lucky' to receive favorable assessments from firms that hire earlier are paid more because average productivities of their coworkers are higher. In a subset of equilibria in which firms hire all workers they think are of high type, there is a positive relationship between firm size and wage. Firms that hire earlier hire more workers as there are more high type workers in the applicant pool to choose from. The model also predicts that productive workers can remain unemployed as firms can not tell them apart from other less productive ones. The

\footnotetext{
${ }^{3}$ Models of labor market learning (e.g.: Farber and Gibbons 1996) and statistical discrimination (e.g.: Coate and Loury 1993) are all based on the same assumption of imperfect information about individual worker's productivity.
} 
equilibrium unemployment is increasing in reservation wage.

We explore several extensions of the basic model. While there are multiple equilibria in the basic model, equilibrium is unique in an extended model where firms differ in productivity. In the equilibrium, firms with higher productivities offer higher wages, hire more workers and make more profits. Thus, there is a size-wage premium for workers conditional on type. Further, even if high productivity workers and firms are not perfectly matched, there exists positive sorting in the sense that the proportion of high productivity workers in the workforce is increasing in firm productivity, similar to Shimer (2005). In another extension we assume firms' abilities to differentiate worker types differ. In equilibrium, firms with better information always earn higher profits, but the order of hiring depends on relative scarcity of high productivity workers in the applicant pool. ${ }^{4}$

While we only consider interactions between firms and workers in our model, the analyses shed lights on inter-industry wage differentials as well..$^{5}$ In a market with different industries competing for talents, those with higher productivity will draw from the worker pool first, but only imperfectly. Thus there would exist both assortative matching and a true industry wage effect controlling for worker type, consistent with empirical results examined in Gibbons and Katz (1992). ${ }^{6}$

It is important to emphasize from the outset that the setup of sequential wage

\footnotetext{
${ }^{4}$ When there are more low type workers than high type ones in the market, marginal benefits of cherry-picking is high, and firms with better information will hire earlier. This results in a unique equilibrium featured by size-wage premium and assortative matching. When there are more high type workers than low type workers, marginal benefit of cherry-picking is low, equilibrium may or may not exist.

${ }^{5}$ In this regard, our model is comparable to those by Montgomery (1991) and Shimer (2005) which also provide insight on inter-industry wage differential.

${ }^{6}$ Gibbons and Katz (1992) report two major empirical findings using a sample of displaced workers from the Current Population Surveys. First, wage regressions for industry-switchers suggest there is a true industry wage effect not explained by individual unobserved heterogeneity. Second, workers maintain some portion of their pre-displacement industry wage premiums when they are re-employed. This is consistent with our model as those who were hired in high-wage industries are on average more productive in unobserved dimensions.
} 
posting is in no way essential for our main results, although it significantly simplifies the analysis. In an alternative model in which firms post wages and make job offers simultaneously, no pure strategy equilibrium exists. But a mixed strategy equilibrium would have similar results as the sequential model. Since workers always accept the highest wage offer, the hiring process is still characterized by firms sequentially cherry-picking workers. Wage dispersion would remain as an equilibrium phenomenon due to imperfect information. We choose to adopt sequential wage posting mainly for two reasons. First, random wage offering as in mixed strategy equilibrium is hard to motivate. ${ }^{7}$ Second, mixed strategy equilibrium in the simultaneous wage posting model is very difficult to handle technically. However, we do provide a simple example in Appendix B to give readers a flavor of a simultaneous wage-posting model.

The rest of the paper is structured as follows. Section 2 presents our basic model. Section 3 extends the model by introducing productivity heterogeneity. In Section 4, we consider an extension in which firms' abilities to assess worker types differ. Section 5 discusses the relationship of this paper to some others in the literature. Section 6 concludes.

\section{The basic model}

\subsection{Setup}

We consider a competitive labor market with no barriers to entry and exit. Firms are ex ante identical, and have a constant return to scale production technology. They produce the same output that are sold in a competitive market at price $P$, which we normalize to 1 .

There is a continuum of workers of measure one, that are of either high or low type. High type and low type workers account for proportion $\alpha$ and $1-\alpha$ of the population,

\footnotetext{
${ }^{7}$ For example, to explains sales behavior, Varian (1980) considers firms playing mixed strategy in pricing. In contrast, in terms of wage policy, firms usually are quite consistent and do not randomize wage offers, as shown by the presence of persistent firm effects in wages.
} 
respectively. A high type worker can produce one unit of output if employed, while a low type worker can produce none. The proportion of the two types and productivities of each type are common knowledge. However, an individual's type is unknown to all parties, including herself. ${ }^{8}$ Workers choose the firm that offers her the highest wage subject to the constraint that it is above her reservation wage $r$. There is no application cost and workers are free to apply to all hiring firms.

When a worker applies to a firm, the firm makes a private assessment ${ }^{9}$ of the job applicant's type. With probability $\beta_{H}$, a high type worker is taken as high type by the firm, thus labeled as " $h$ ". With probability $1-\beta_{H}$, she is mistakenly recognized as low type, or labeled with "l". Similarly, a low type worker is labeled "l" with probability $\beta_{L}$ and " $h$ " with probability $1-\beta_{L}$. We assume all firms have the same ability to differentiate high type workers from low type ones, i.e., they have the same $\beta_{H}$ and $\beta_{L}$. The private assessments of different firms are independent, ${ }^{10}$ thus a worker recognized as low type by one firm may be taken as high type by another.

For simplicity, we let $\beta_{H}=\beta_{L}=\beta .^{11}$ When $\beta=1 / 2$, firms have no ability to differentiate high type workers from low type workers. When $\beta=1$, firms can perfectly distinguish high type from low type workers. When $1>\beta>1 / 2$, firms have some but less than perfect ability to judge worker types, and this is the case we focus on in this paper.

Workers have the same reservation wage $r$, and any wage offer $w<r$ will not be accepted. To eliminate the uninteresting case that $r$ is so high that no firm hires any worker, we assume $r<\alpha$. Thus, a firm could make a profit by hiring all workers or a random subset at their reservation wage $r$.

The job market works in a sequential manner, consisting of many rounds of auc-

\footnotetext{
${ }^{8}$ An alternative assumption is that workers know their own types, but are prohibited from sending signal to firms. Our model thus departs from the signaling literature but resembles statistical discrimination models such as Coate and Loury (1993).

${ }^{9}$ One may simply think this as a job interview.

${ }^{10}$ Our main results do not change as long as these assessments are not perfectly correlated. Assuming independence simplifies our analyses, though.

${ }^{11}$ None of our substantive results will change without this assumption.
} 
tions among hiring firms. Each round, firms that have not hired yet post wages they are willing to offer to some workers in the remaining pool of applicants. The one with the highest wage wins the right to hire. In case several firms tie at the highest wage, one firm is randomly chosen as the winner. The winning firm can then offer to hire selected workers among the remaining pool of applicants at the posted wage. ${ }^{12}$ Upon receiving an offer from the firm, workers decide whether to accept the offer or not. After that, the game moves to the next round with the same process repeated for firms who have not hired and for workers who remain unemployed. The game ends when no firm finds it profitable to post a wage that will be accepted. That is, firms are unwilling to hire any unemployed worker at a wage greater than their reservation wage. Production then starts, and active firms, those who have hired a positive measure of workers, realize their profits.

In this model, an equilibrium is characterized by the number of active firms $K$, unemployment rate $u$, and wage distribution $F(w)$, such that the following conditions are satisfied:

1. Workers maximize the wage income they receive, provided the wage offered is greater than their reservation wage $r$,

2. Firms make wage offers to maximize profit,

3. Firms update beliefs about workers' types using Bayes rule.

\subsection{Main results}

To start, note that because firms are ex ante identical, they must make the same profit in equilibrium. Otherwise, firms that make lower profit will mimic the behavior of those earning higher profit.

A firm actually makes two choices in the recruiting process: to post a wage, and decide whom to hire at the posted wage if it wins the right to hire. Firms face observationally two different groups of workers: those it labels as " $h$ " and those it labels as

\footnotetext{
${ }^{12}$ We do not allow the trivial case that winning firms make offer to no workers. Thus firms always make offers to a positive measure of workers when it wins the right to hire
} 
"l". Therefore, a firm can make offers in three different ways if wins the right to hire in a round: either to all workers randomly irrespective of the labels, or only to those " $h$ " workers, or only to " $l$ " workers. The competition between ex ante identical firms, however, forces a firm to hire only those it labels as " $h$ ".

Lemma 1. In equilibrium, a firm hires only those it labels as " $h$ ".

Proof. See Appendix A.

The intuition for this result is straightforward. As firms compete for the right to hire in a round, they have pushed the winning bid so high, such that hiring those "l" workers would reduce the profit of the hiring firm given its posted wage. What this implies is that, in equilibrium, firms take turns cherry-picking more productive workers.

Lemma 2. In equilibrium, firms make zero profit.

Proof. See Appendix A.

The above two results suggest that firms' expected profit from each worker hired is zero. A firm can therefore hire any portion of those it thinks as high type in equilibrium. In what follows we let $\delta_{k} \in(0,1]$ denotes the proportion of workers firm $k$ hires in an equilibrium.

We summarize our results so far in the following proposition.

Proposition 1. There exist multiple equilibria. In any equilibrium, firms pay workers their average productivities. Also, both average productivities and wages decline in $k$, the order of hiring.

Proof. The results follow directly from Lemma 1 and Lemma 2. Let firm $k$ make offers to $\delta_{k}$ proportion of those it labels as " $h$ ". It suffices to show that average productivity of workers hired by firm $k$ (denoted by $H_{k}$ ) is greater than that of firm $k+1$ (denoted by $H_{k+1}$ ), as $w_{k}=H_{k}$ and $w_{k+1}=H_{k+1}$. Let the applicant pool facing firm $k$ consists $\tilde{n}_{k}$ measure of high workers and $\tilde{m}_{k}$ measure of low type workers. We have

$$
H_{k}=\frac{\tilde{n}_{k} \beta}{\tilde{n}_{k} \beta+\tilde{m}_{k}(1-\beta)}
$$


The applicant pool firm $k+1$ will choose from consists of $\tilde{n}_{k+1}=\left(1-\delta_{k} \beta\right) \tilde{n}_{k}$ measure of high type workers and $\tilde{m}_{k+1}=\left[1-\delta_{k}(1-\beta)\right] \tilde{m}_{k}$ measure of low type workers. Hence,

$$
H_{k+1}=\frac{\left(1-\delta_{k} \beta\right) \tilde{n}_{k} \beta}{\left(1-\delta_{k} \beta\right) \tilde{n}_{k} \beta+\left[1-\delta_{k}(1-\beta)\right] \tilde{m}_{k}(1-\beta)} .
$$

Clearly, $H_{k}>H_{k+1}$ given that $1>\beta>1 / 2$ and $0<\delta_{k} \leq 1$.

It remains to show that there exists at least two active firms in the market. This is guaranteed by the assumption that $r<\alpha$. Note that the average productivity of workers that firm 2 labels as " $h$ " is

$$
H_{2}=\frac{\left(1-\delta_{1} \beta\right) \alpha \beta}{\left(1-\delta_{1} \beta\right) \alpha \beta+\left[1-\delta_{1}(1-\beta)\right](1-\alpha)(1-\beta)} \geq \alpha,
$$

which is greater than the reservation wage $r$, so firm 2 will be active.

We next analyze a subset of equilibria in which firms hire every worker they think is of high type, i.e., $\delta_{k}=1$ for all $k$. It is not hard to show that as long as $\delta_{k}=\delta \in(0,1]$ for all $k$, the corresponding equilibria have the same properties. However, for ease of exposition, we only look at the special case of $\delta=1$. This is formally stated in the following assumption ${ }^{13}$.

Assumption 1. Firms treat observationally identical workers in the same way. That is, if a firm makes an offer to any worker, then it must also make the same offer to other workers who have the same expected productivity from the firm's perspective.

Proposition 2. Under Assumption 1, the equilibrium is characterized by employer size-wage premium. Firms that offer higher wages (both unconditionally and conditional on type) also hire more workers.

Proof. Note this is just the special case with $\delta_{k}=1$ as considered in Proposition 1. In general, the average productivity of workers at firm $k$ is

$$
H_{k}=\frac{\alpha \beta(1-\beta)^{k-1}}{\alpha \beta(1-\beta)^{k-1}+(1-\alpha) \beta^{k-1}(1-\beta)} .
$$

\footnotetext{
${ }^{13}$ In an environment when firms know worker types perfectly, Shimer (2005) similarly assumes that firms' wage offers may be conditional on a worker's type but not on her individual identity.
} 
The measure of workers firm $k$ hires equals $N_{k}=\alpha(1-\beta)^{k-1} \beta+(1-\alpha) \beta^{k-1}(1-\beta)$. Clearly, both $H_{k}$ and $N_{k}$ decrease as $k$ increases. Hence, there is a positive relationship between firm size and wage.

Again, note that as long as $\delta_{k}=\delta<1$ for all $k$, there is a size-wage effect in equilibrium, but with $H_{k}$ and $N_{k}$ formulated differently.

After firms $1,2, \cdots, k-1, k$ have hired, the measure of workers remains to be hired equals $R_{k}=\alpha(1-\beta)^{k}+(1-\alpha) \beta^{k}$, and the average productivity of the remaining workers will be

$$
\alpha_{k+1}=\frac{\alpha(1-\beta)^{k}}{\alpha(1-\beta)^{k}+(1-\alpha) \beta^{k}}=\frac{\alpha[(1-\beta) / \beta]^{k}}{\alpha[(1-\beta) / \beta]^{k}+(1-\alpha)} .
$$

Note that both $R_{k}$ and $\alpha_{k+1}$ are strictly decreasing in $k$. As more and more firms have hired, the proportion of high type workers in the remaining pool decreases, so does the measure of unemployed workers. At certain point, it becomes unprofitable for another firm to hire, as the expected benefit from hiring a worker the firm recognizes as high type drops below the reservation wage $r$. This implies that the equilibrium number of firms $K$ is determined by the condition

$$
H_{K} \geq r>H_{K+1}
$$

Corollary 1. In the equilibrium characterized in Proposition 2, there exists a finite number of active firms. Also, number of active firms $K$ is decreasing in workers' reservation wage $r$, while equilibrium unemployment rate is increasing in $r$.

Proof. To see that number of active firms is finite, note that $H_{k}$ strictly decreases in $k$ and goes to zero as $k$ goes to infinite. Because $H_{K} \geq r>H_{K+1}, K$ has to be a finite number. To show the second part, we note that the measure of workers remain unemployed after round $k$ equals $R_{k}=\alpha(1-\beta)^{k}+(1-\alpha) \beta^{k}$. The measure of unemployed workers equals $R_{K}$. As $K$ decreases in $r, R_{K}$ increases in $r$. Hence, we conclude that the measure of unemployed workers, also the unemployment rate, strictly increases in the reservation wage $r$.

In the equilibrium, there are $\alpha(1-\beta)^{K}$ measure of unemployed high type workers and $(1-\alpha) \beta^{K}$ measure of unemployed low type workers, both increasing with the 
reservation wage $r$. In addition, the proportion of high type workers among unemployed workers, $\alpha(1-\beta)^{K} /\left[\alpha(1-\beta)^{K}+(1-\alpha) \beta^{K}\right]$ decreases in $K$ and thus, increases in the reservation wage $r$. As one interpretation of $r$ could be the minimum wage, our model predicts that an increase in the binding minimum wage results in larger proportion of high productivity workers to be unemployed.

\section{Heterogeneity in Firm's Productivity}

In the real world, firms are obviously quite different in many dimensions. The implications of such heterogeneities on labor market outcomes deserve serious examination. Therefore, this section extends the basic model and allow firms to be different ex ante in terms of productivity. For notational purpose, we index firms by the rank order of their productivities, or production technology. Thus firm $i$ has production technology $\psi_{i}$ which ranks $i$ th among all firms. Worker productivity and firm production technology enter into the production function multiplicatively. A high type worker hired by firm $i$ produces $\psi_{i}$ units of output, while a low type worker still produces none.

Lemma 3. In equilibrium, active firms' profits strictly increase in their productivity, i.e., for two firms, firm $i$ with $\psi_{i}$ and firm $j$ with $\psi_{j}$, both of which hire a positive measure of workers in an equilibrium, $\psi_{i}>\psi_{j}$ implies $\Pi_{i}>\Pi_{j}$.

Proof. Suppose there is an equilibrium in which firm $j$ hires in the $k$-th round at $w_{k}$ and employs $\bar{n}_{k}$ measure of high type workers and $\bar{m}_{k}$ measure of low type workers. Firm $j$ 's total profit is $\Pi_{j}=\bar{n}_{k} \psi_{j}-\left(\bar{n}_{k}+\bar{m}_{k}\right) w_{k}$. Firm $i$ could at least mimic firm $j$ by offering $w_{k}+\epsilon$ and hiring in the $k$-th round, thus realize a profit of $\Pi_{i}^{k}=\bar{n}_{k} \psi_{i}-\left(\bar{n}_{k}+\right.$ $\left.\bar{m}_{k}\right) w_{k}>\Pi_{j}$. Hence we have $\Pi_{i} \geq \Pi_{i}^{k}>\Pi_{j}$.

Lemma 3 indicates that some firms get positive profit in equilibrium. As a result, these firms will hire every worker labelled as " $h$ ". Hence, in equilibrium, there is finite number of active firms (hire a positive measure of workers) as the reservation 
$r>0$. If we denote the total number of active firms as $K$, this result also implies that active firms are firms $1,2, \ldots, K$.

Lemma 4. In equilibrium, the wage offers by active firms strictly decrease. That is, if $w_{k}$ is the wage offer in the $k$-th round, then $w_{k}>w_{k+1}$ for any $k$.

Proof. We prove this result by contradiction. Suppose there were one equilibrium in which the equilibrium wage offers for two consecutive rounds are such that $w_{k} \leq w_{k+1}$. Let the applicant pool for the $k$-th round consists of $\tilde{n}_{k}$ measure of high type, $\tilde{m}_{k}$ measure of low type workers. Let firm $j$ be the one that hires in the $(k+1)$-round, facing $\tilde{n}_{k+1}$ measure of high type and $\tilde{m}_{k+1}$ measure of low type workers. Clearly $\tilde{n}_{k+1}+\tilde{m}_{k+1}<\tilde{n}_{k}+\tilde{m}_{k}$ and $\tilde{n}_{k+1} / \tilde{m}_{k+1}<\tilde{n}_{k} / \tilde{m}_{k}$ because the firm that hires in round $k$ proportionally select better workers from the pool. Thus firm $j$ has a clear incentive to deviate by offering $w_{k}+\epsilon$ and get the right to hire in round $k$, where it faces strictly better applicants pool (in terms of both total measure of workers and proportion of high productivity workers) and lower wages.

When the difference in production technology is too large, one firm could dominate the market. For example, it could be the case that $\psi_{1}$ is big enough such that

$$
\psi_{1} \frac{\alpha(1-\beta)}{\alpha(1-\beta)+(1-\alpha) \beta}>\psi_{2} H_{2} ;
$$

firm 1 can profitably hire every job applicant at a wage $w \geq \psi_{2} H_{2}$. The rest of firms hire no worker in equilibrium. The next assumption rules out this possibility.

Assumption 2. The production technology difference is not too large, specifically,

$$
\max _{i<j}\left\{\frac{\psi_{i}}{\psi_{j}}\right\} \leq \Omega(\alpha, \beta) \equiv \frac{\alpha(1-\beta) \beta+(1-\alpha) \beta^{2}}{\alpha(1-\beta) \beta+(1-\alpha)(1-\beta)^{2}} .
$$

Lemma 5. Under Assumption 2, no firm hires any worker labeled as "l" in equilibrium.

Proof. Consider firm $k$ that hires in the $k$-th round, facing an applicant pool with $\alpha_{k}$ proportion of high type and $1-\alpha_{k}$ proportion of low type workers. It is necessary that $w_{k} \geq \frac{\alpha_{k} \beta \psi_{K+1}}{\alpha_{k} \beta+\left(1-\alpha_{k}\right)(1-\beta)}$, where firm $K+1$ is an inactive firm, as otherwise it could offer a wage $w_{k}+\varepsilon$ and realizes a positive profit. 
In this case, however, it will not be profitable for any firm to hire "l" workers. This is so as the expected productivities of those workers are strictly less than the wage,

$$
\frac{\alpha_{k}(1-\beta) \psi_{k}}{\alpha_{k}(1-\beta)+\left(1-\alpha_{k}\right) \beta}<\frac{\alpha_{k} \beta \psi_{K+1}}{\alpha_{k} \beta+\left(1-\alpha_{k}\right)(1-\beta)} \leq w_{k}
$$

The first inequality holds because $\frac{\psi_{k}}{\psi_{K+1}} \leq \max _{i<j}\left(\frac{\psi_{i}}{\psi_{j}}\right)<\Omega(\alpha, \beta)<\Omega\left(\alpha_{k}, \beta\right)$. Note that for any $k>1$ we have $\alpha_{k}<\alpha$ as the average productivities of the applicant pool deteriorate over time.

Lemma 6. In equilibrium, high productivity firms always hire before low productivity firms.

Proof. First, note that Lemma 3 indicates that all active firms except the last (firm $K)$ make strictly positive profits, and they hire every worker labeled as " $h$ ".

Now suppose Lemma 6 were not true, then there exists at least one equilibrium in which firm $j$ hires in the $k$-th round and firm $i$ hires in the $k+1$-th round, but with $\psi_{j}<\psi_{i}$.

Let the applicant pool facing firm $j$ in the $k$-th round consists $\tilde{n}_{k}$ measure of high type, $\tilde{m}_{k}$ measure of low type workers. The expected profit for firm $j$ is

$$
\Pi_{j}^{k}=\tilde{n}_{k} \beta \psi_{j}-\left[\tilde{n}_{k} \beta+\tilde{m}_{k}(1-\beta)\right] w_{k}
$$

However, by waiting to hire in the $k+1$-th round at wage $w_{k+1}$, firm $j$ would get

$$
\Pi_{j}^{k+1}=\tilde{n}_{k}(1-\beta) \beta \psi_{j}-\left[\tilde{n}_{k}(1-\beta) \beta+\tilde{m}_{k} \beta(1-\beta)\right] w_{k+1} .
$$

Meanwhile,firm $i$ 's profit is:

$$
\Pi_{i}^{k+1}=\tilde{n}_{k}(1-\beta) \beta \psi_{i}-\left[\tilde{n}_{k}(1-\beta) \beta+\tilde{m}_{k} \beta(1-\beta)\right] w_{k+1} .
$$

By hiring in the $k$-th round at wage $w_{k}$, it would get

$$
\Pi_{i}^{k}=\tilde{n}_{k} \beta \psi_{i}-\left[\tilde{n}_{k} \beta+\tilde{m}_{k}(1-\beta)\right] w_{k}
$$

To be an equilibrium, it must be true that $\Pi_{i}^{k} \leq \Pi_{i}^{k+1}$ and $\Pi_{j}^{k} \geq \Pi_{j}^{k+1}$. Substituting the above profit equations and combining the two inequalities, we have $\psi_{j} \geq \psi_{i}$, which contradicts the condition $\psi_{j}<\psi_{i}$. 
We next determine the number of firms $K$ and the behavior of firm $K$. Because all firms hiring before $K$ select workers they label as " $h$ ", the applicant pool facing firm $K$ consists of $(1-\beta)^{K-1} \alpha$ high type workers and $\beta^{K-1}(1-\alpha)$ low type workers. This indicates that the number of active firms is determined by the condition

$$
\frac{\alpha(1-\beta)^{K-1} \beta \psi_{K}}{\alpha(1-\beta)^{K-1} \beta+(1-\alpha) \beta^{K-1}(1-\beta)} \geq r>\frac{\alpha(1-\beta)^{K} \beta \psi_{K+1}}{\alpha(1-\beta)^{K} \beta+(1-\alpha) \beta^{K}(1-\beta)} .
$$

In competing the right to hire in the $K$-th round, firm $K+1$, who has the highest productivity among those not hiring, is willing to offer

$$
w_{K+1}^{K}=\frac{\alpha(1-\beta)^{K-1} \beta \psi_{K+1}}{\alpha(1-\beta)^{K-1} \beta+(1-\alpha) \beta^{K-1}(1-\beta)} .
$$

Consequently, any active firm who wins the right to hire in this round has to offer at least this much. However, if $w_{K+1}^{K}$ happens to be less than workers' reservation wage, then the firm has to offer at least $r$. Clearly, the firm does not have any incentive to offer more than that either, thus

$$
w_{K}=\max \left\{r, \frac{\alpha(1-\beta)^{K-1} \beta \psi_{K+1}}{\alpha(1-\beta)^{K-1} \beta+(1-\alpha) \beta^{K-1}(1-\beta)}\right\} .
$$

In the special case of

$$
r=\frac{\alpha(1-\beta)^{K-1} \beta \psi_{K}}{\alpha(1-\beta)^{K-1} \beta+(1-\alpha) \beta^{K-1}(1-\beta)},
$$

firm $K$ makes zero profit and may hire any positive proportion of workers it labels as " $h$ ". Otherwise it makes positive profit and hires all " $h$ " workers. Following the same reasoning, one can show that $w_{k}$ is determined by the condition $\Pi_{k+1}^{k}=\Pi_{k+1}^{k+1}$, which makes the firm hiring in the $k+1$ round indifferent between hiring in the $k$-th and $k+1$-th rounds. The following proposition proves formally that this is an equilibrium.

Proposition 3. Under Assumption 2, there exists a unique equilibrium with the following properties:

(a) There are $K$ active firms, with $K$ determined by the condition (2).

(b) Firms hire according to the rank order of their productivities. That is, firm $k$ $(\leq K)$ with $\psi_{k}$ hires in the $k$-th round. 
(c) Active firms hire all workers they think are of high type but none they think are of low type. The last hiring firm K, though, hire any proportion of workers it considers as high type should condition (4) holds.

(d) Wages decrease in each round. Further, they are recursively determined starting from $w_{K}$ in (3). In general $w_{k}$ is determined such that firm $k+1$ is just indifferent between hiring in the $k+1$-th round at wage $w_{k+1}$ and hiring in the $k$-th round at wage $w_{k}$

(e) All active firms make positive profits except firm $K$, which makes zero profit if condition (4) happens to hold. Total profits decrease in $k$.

(f) The equilibrium exhibits a positive relationship between firm sizes and wages.

Proof. See Appendix A.

This extended model also sheds light on inter-industry wage differential and sorting between workers and industries. In a labor market in which different industries compete for workers, those who have higher productivities find it profitable to offer higher wages in order to select better workers, due to the complementarity between worker and firm productivities. Thus our model also has the flavor of efficiency wage models as discussed by Krueger and Summers (1988). Note that the size-wage relationship no longer needs to hold here as the size of an industry can be considered as exogenously given by technology and market demand.

\section{Heterogeneity in Firm's Abilities to Assess Worker Types}

In this section we consider a different extension of the basic model, allowing firms to have the same productivity but different abilities to tell high type workers from low type ones. We index firms by the rank order of their information parameter $\beta$, i.e, for two firms $i$ and $j, i<j$ implies that $\beta_{i}>\beta_{j}$. For all $i, \beta_{i} \in(1 / 2,1)$. 
Proposition 4. In equilibrium, the winning firm at each round hires all workers it labels as " $h$ ", none of those it labels as "l". Wages offered decline in $k$, the order of hiring. Also, active firms' profit $\Pi_{i}$ increases in firm's information parameter $\beta_{i}$.

Proof. See Appendix A.

As in the previous section, equilibrium wage offers are determined in a backward way starting from the last round. Given the result of the proposition, we know that active firms in the market could only be firms $1,2, \ldots, K$. Let the firm who hires in the last round be firm $j$, then

$$
w_{K}=\max \left\{r, \frac{\alpha\left[\prod_{k=1}^{K}\left(1-\beta_{k}\right)\right] \beta_{K+1} /\left(1-\beta_{j}\right)}{\alpha\left[\prod_{k=1}^{K}\left(1-\beta_{k}\right)\right] \beta_{K+1} /\left(1-\beta_{j}\right)+(1-\alpha)\left[\prod_{k=1}^{K} \beta_{k}\right]\left(1-\beta_{K+1}\right) / \beta_{j}}\right\} .
$$

That is, firm $j$ hiring in the last round has to pay the maximum of reservation wage $r$ and the highest wage firm $K+1$ (which has the best information among all inactive firms) is willing to offer.

Similarly, the equilibrium wage offered for the $(K-1)$-th round will be such that the firm hiring in the $K$-th round is indifferent between winning the $K$-th round and the $(K-1)$-th round. This is also true for any round $k$. The following preliminary result shows how the order or hiring will be determined:

Lemma 7. At any round $k$, let the measure of high type and low type workers be $\tilde{n}_{k}$ and $\tilde{m}_{k}$, respectively. Suppose in equilibrium firm $i$ and $j$ hire at round $k$ and $k+1$, respectively. If $\tilde{n}_{k}<(>) \tilde{m}_{k}$, then it must be that $\beta_{i}>(<) \beta_{j}$.

Proof. See Appendix A.

At each round, profit-maximizing firms decide whether to win in the current round by biding the highest wage or not to win. A firm expects to pay lower wage by waiting for a few rounds. However, waiting also lowers the quality of workers it gets. Lemma 7 indicates that how a firm balance the trade-off in a round depends on the composition of job applicants in the pool.

In what follows, we separately discuss two cases according to the initial composition of workers in the market: there are more low type workers, $\alpha<1 / 2$, and there 
are more high type workers, $\alpha>1 / 2$. We also briefly discuss the case when $\alpha=1 / 2$ in Appendix A (Lemma A5 and A6).

\subsection{More low type workers}

When $\alpha<1 / 2$, there are relatively few high type workers in the market initially. Securing a better applicant pool becomes the main concern for every firm that intends to hire. Those with informational advantage will bid more aggressively for the right to hire earlier. Hence, firms with larger $\beta$ s always hire earlier than firms with smaller ones. The order of hiring is uniquely determined. We summarize the result as follows:

Proposition 5. When $\alpha<1 / 2$, there exists a unique equilibrium in which firms hire in the order of $\beta$. Firms $1,2, \ldots, K$ are active in the market, where $K$ is determined by the condition

$$
\begin{aligned}
& \frac{\alpha \prod_{i=1}^{K-1}\left(1-\beta_{i}\right) \beta_{K}}{\alpha \prod_{i=1}^{K-1}\left(1-\beta_{i}\right) \beta_{K}+(1-\alpha) \prod_{i=1}^{K-1} \beta_{i}\left(1-\beta_{K}\right)} \geq r> \\
& \frac{\alpha \prod_{i=1}^{K}\left(1-\beta_{i}\right) \beta_{K+1}}{\alpha \prod_{i=1}^{K}\left(1-\beta_{i}\right) \beta_{K+1}+(1-\alpha) \prod_{i=1}^{K} \beta_{i}\left(1-\beta_{K+1}\right)}
\end{aligned}
$$

Proof. See Appendix A.

Definition 1. The distribution of $\beta$ is not too dispersed if for any two consecutively ranked firms $i, i+1$ with $\beta_{i}$ and $\beta_{i+1}$ respectively, $\left(1-\beta_{i}\right) /\left(1-\beta_{i+1}\right) \geq \beta_{i}$.

Corollary 2. Suppose $\alpha<1 / 2$. There exists a positive relationship between firm sizes and wages if the distribution of $\beta$ is not too dispersed.

Proof. See Appendix A.

We also show in Appendix A (Lemma A6) that in the case of $\alpha=1 / 2$, hiring in the order of $\beta,(1,2, \ldots K)$, is still an equilibrium. However, in certain cases there also exists another equilibrium in which firm 2 hires first, i.e, firms hire in the order $(2,1, \ldots K)$. 


\subsection{More high type workers}

When $\alpha>1 / 2$, the quality of job applicants in the pool is so good that firm 1 with the best information may afford to wait for one more round. Waiting costs firm 1 in terms of the quality of applicants. However, given the facts that the initial pool is very good and the rest of firms are not as good as firm 1 in selecting high type workers, the remaining pool should not be too bad. It turns out that in this case, the benefit from paying a lower wage will more than offset the cost from reduced quality. Firm 1 therefore does not want to hire in the first round.

Proposition 6. When $1 / 2<\alpha \leq \beta_{2}$, there exists a unique equilibrium in which firms hire in the order of $(2,1, \ldots K)$, where the number of active firms $K$ is determined by the condition in (5).

Proof. See Appendix A.

As $\alpha>1 / 2$, firm 1 is willing to let firm 2 hire first, as firm 2's ability in selecting high types workers is not as good as firm 1's. Firm 1 finds the wage $w_{2}$ a bargain price given the quality of the remaining applicants. In addition, the condition $\alpha \leq \beta_{2}$ also implies that after firm 2 has hired in the first round, there are more low type workers in the remaining pool, and thus, firm 1 has no incentives to postpone hiring again. This makes the hiring order unique and stable.

On the other hand, when the initial pool of workers is so good, $\alpha>\beta_{2}$, no hiring order is stable. Even after firm 2 has hired, the remaining pool still consists of more high type than low type workers, firm 1 again would have an incentive to postpone hiring, unless there are only two rounds, $K=2$. However, if firms other than firm 1 were to hire in the second round, firm 2 would rather not to hire in the first round. But no other firm would not want to hire in the first round either. They are not as good as firm 1 and 2 in choosing the high type workers, thus the wage has to be paid is the first round is simply too high to appeal to them.

Of course, when there are just one or two active firms, this will not be a problem. First, when $K=1$, only firm 1 will hire and the rest of firms remain inactive. ${ }^{14}$ Next,

\footnotetext{
${ }^{14}$ This happens under condition that $\frac{\alpha \beta_{1}}{\alpha \beta_{1}+(1-\alpha)\left(1-\beta_{1}\right)} \geq r>\frac{\alpha\left(1-\beta_{1}\right) \beta_{2}}{\alpha\left(1-\beta_{1}\right) \beta_{2}+(1-\alpha) \beta_{1}\left(1-\beta_{2}\right)}$. Firm 1 pay a
} 
when $K=2$, both firm 1 and 2 are active in the market. The only possible hiring order is firm 2 hires before firm 1 , which is stable. ${ }^{15}$ But with more than two firms ( $K \geq 3$ ), equilibrium does not exist, as shown in the following proposition.

Proposition 7. When $\alpha>\beta_{2}$, no equilibrium exists if the number of active firms $K \geq 3$, in which $K$ is determined by condition (5).

Proof. See Appendix A.

\section{Related Literature}

Our model is closely related to search and matching models. Although these models sometimes generate similar implications as we do, the types of frictions under consideration are quite different. Random search models typically assume that workers do not fully know potential jobs, thus have to either wait for a time period or incur a direct cost to sample from the pool of job offers. In the on-the-job search model of Burdett and Mortensen (1998), workers search randomly and gradually move from wage of $w_{1}=\max \left\{r, \frac{\alpha \beta_{1}}{\alpha \beta_{1}+(1-\alpha)\left(1-\beta_{1}\right)}\right\}$.

${ }^{15}$ This happens when

$$
\frac{\alpha\left(1-\beta_{2}\right) \beta_{1}}{\alpha\left(1-\beta_{2}\right) \beta_{1}+(1-\alpha) \beta_{2}\left(1-\beta_{1}\right)} \geq r>\frac{\alpha\left(1-\beta_{1}\right)\left(1-\beta_{2}\right) \beta_{3}}{\alpha\left(1-\beta_{1}\right)\left(1-\beta_{2}\right) \beta_{3}+(1-\alpha) \beta_{1} \beta_{2}\left(1-\beta_{3}\right)} .
$$

Firm 1 hires in the second round and pay

$$
w_{2}=\max \left\{r, \frac{\alpha\left(1-\beta_{2}\right) \beta_{3}}{\alpha\left(1-\beta_{2}\right) \beta_{3}+(1-\alpha) \beta_{2}\left(1-\beta_{3}\right)}\right\},
$$

makes a profit of

$$
\Pi_{1}^{2}=\alpha\left(1-\beta_{2}\right) \beta_{1}-\left[\alpha\left(1-\beta_{2}\right) \beta_{1}+(1-\alpha) \beta_{2}\left(1-\beta_{1}\right)\right] w_{2},
$$

Note that $w_{1}$ is determined by the condition $\Pi_{1}^{1}=\Pi_{1}^{2}$, where $\Pi_{1}^{1}=\alpha \beta_{1}-\left[\alpha \beta_{1}+(1-\alpha)\left(1-\beta_{1}\right)\right] w_{1}$. Thus

$$
\begin{gathered}
w_{1}=\frac{\alpha \beta_{1} \beta_{2}+\left[\alpha\left(1-\beta_{2}\right) \beta_{1}+(1-\alpha) \beta_{2}\left(1-\beta_{1}\right)\right] w_{2}}{\alpha \beta_{1}+(1-\alpha)\left(1-\beta_{1}\right)}, \\
\Pi_{2}^{1}=\alpha \beta_{2}-\left[\alpha \beta_{2}+(1-\alpha)\left(1-\beta_{2}\right)\right] w_{1}, \\
\Pi_{2}^{2}=\alpha\left(1-\beta_{1}\right) \beta_{2}-\left[\alpha\left(1-\beta_{1}\right) \beta_{2}+(1-\alpha) \beta_{1}\left(1-\beta_{2}\right)\right] w_{2} .
\end{gathered}
$$

We can check that $\Pi_{2}^{1}>\Pi_{2}^{2}$, thus as long as the condition $\Pi_{2}^{1} \geq 0$ holds, there exists an equilibrium in which firm 2 hires before firm 1. 
low paying jobs to high paying jobs. Identical firms offer different wages in the equilibrium, as those who offer higher wages attract more workers at the expense of enjoying lower per worker profit. Thus the model also generates size-wage premium in the equilibrium, However, their underlying intuition is quite different than ours. Because workers are homogeneous in their model, large firms pay more to keep a larger workforce. In our model, large firms are willing to pay more because they want to select better workers from a heterogeneous population of job candidates.

The directed search literature restricts the number of jobs a worker can apply at a time, thus creates a coordination problem among fellow job seekers. In Shimer (2005), heterogeneous workers and firms interact in a static environment. The model generates wage dispersion as well as positive sorting of workers and firms. However, it does not predict size-wage premium as a firm is just characterized by one job vacancy. On the other hand, Shimer (2005) captures the coexistence of unemployment and job vacancies, which is beyond the scope of this paper. Shimer (2005) also consider more general production functions (see also Shi 2002a). Similarly, Acemoglu and Shimer (2000) study how labor market coordination friction also induce ex ante identical firms to adopt different technologies. Albrecht et al. (2006) and Galenianos and Kircher (2009) extend the Shimer model and allow workers to send multiple (but still finite number of) applications. Shi (2002b) generates size-wage premium based on coordination frictions in both product market and labor market.

Many macroeconomic models of labor market rely on an aggregate matching function without specifying the exact source of market frictions (see Pissarides 2000). The micro-foundations of a well-performed matching function includes random search (urn-ball model), coordination friction, the stock-flow analysis of Coles and Smith (1998), and the model of Lagos (2000) which considers optimal decisions across spatially distinct locations.

The paper falls into a large literature on labor market information that dates back at least to Stigler (1962), who studies information about jobs for workers and initiated the whole search literature. Spence (1973) shows how high productivity job applicants could send costly signals to prospective employers in order to be separated from 
low productivity workers. Similarly, the statistical discrimination literature (for example, Coate and Loury 1993, Moro and Norman 2004) analyzes how personal characteristics such as race and gender can be used to form conditional expectations in labor markets with imperfection information, and lead to self-fulfilling vicious cycles. Farber and Gibbons (1996) study wage dynamics following initial hiring as employer gradually learn about worker productivity. More recently, Grossman (2004) demonstrates that the combination of imperfect information with national differences in the distribution of worker talents can be an independent source of comparative advantage, and lead to trade in two otherwise identical countries. Grossman (2004) motivates imperfect information with team work in production and labels this "incomplete labor contract", as no contract can be written conditional on each individual worker's marginal product.

Recently, there is also a growing literature exploring the role of informational friction in the framework of search. This includes Guerrieri (2008), Faig and Jerez (2005), and Guerrieri et al. (2008). These models combine search (coordination) friction with imperfect information, thus are different from our model. Their predictions are also different from ours.

\section{Conclusions}

Information plays a very important role in many labor markets. With perfect information, the law of one price must hold, with workers of identical productive capabilities being paid equal wages. However, real world labor contracts are seldom perfect as employers only have imperfect knowledge of workers' productivities. In this case, competing force is not enough to ensure workers to be paid according to their talents. Workers of different abilities can be paid the same wage, while workers of the same ability can be paid differently.

In this paper we formalize this intuition and analyze a model of imperfect information in a competitive setting. Firms compete by offering higher wages in order to "cherry-pick" better workers. Our model thus offers an alternative way to under- 
stand many important labor market phenomenons, including non-degenerated firm size distribution, persistent wage dispersions, employer size-wage premium, and positive sorting of firms and workers. The model also sheds light on inter-industry wage differential and sorting between workers and industries.

Finally, our model is highly stylized and meant to be so. Similar to Shimer (2005), the model needs to be extended to a dynamic framework to make serious empirical predictions. In a dynamic model, firms gradually learn more about worker productivities and wages will evolve accordingly, as in Farber and Gibbons (1996). It would also be feasible to combine imperfect information with other labor market frictions in order to provide a more accurate description of actual labor markets.

\section{References}

Abowd, J., F. Kramarz, and D. Margolis (1999). High wage workers and high wage firms. Econometrica 67, 251-333.

Acemoglu, D. and R. Shimer (2000). Wage and technology dispersion. Review of Economic Studies 67(4), 585-607.

Albrecht, J., P. A. Gautier, and S. Vroman (2006). Equilibrium directed search with multiple applications. Review of Economic Studies 73(4), 869-891.

Brown, C. and J. Medoff (1989). The employer size-wage effect. Journal of Political Economy 97, 1027-1059.

Burdett, K. and D. T. Mortensen (1998). Wage differentials, employer size, and unemployment. International Economic Review 39, 257-273.

Coate, S. and G. C. Loury (1993). Will affirmative-action policies eliminate negative stereotypes? American Economic Review 83, 1220-1240.

Coles, M. and E. Smith (1998). Marketplaces and matching. International Economic Review 39, 239-254. 
Faig, M. and B. Jerez (2005). A theory of commerce. Journal of Economic Theory $122(1), 60-99$.

Farber, H. S. and R. Gibbons (1996). Learning and wage dynamics. Quarterly Journal of Economics 111(4), 1007-1047.

Galenianos, M. and P. Kircher (2009). directed search with multiple job applications. Journal of Economic Theory 144(2), 445-471.

Gibbons, R. and L. Katz (1992). Does unmeasured ability explain inter-industry wage differentials? Review of Economic Studies 59(3), 515-535.

Grossman, G. M. (2004). The distribution of talent and the pattern and consequences of international trade. Journal of Political Economy 112(1), 209-239.

Guasch, L. J. and A. Weiss (1981). Self-selection in the labor market. American Economic Review 71(3), 275-284.

Guerrieri, V. (2008). Inefficiency unemployment dynamics under asymmetric information. Journal of Political Economy 116(4), 667-708.

Guerrieri, V., R. Shimer, and R. Wright (2008). Adverse selection in competitive search equilibrium. Working Paper.

Krueger, A. and L. Summers (1988). Effciency wages and the inter-industry wage sturcture. Econometrica 56(2), 259-293.

Lagos, R. (2000). An alternative approach to search friction. Journal of Political Economy 108, 851-873.

Montgomery, J. D. (1991). Equilibrium wage dispersion and interindustry wage differentials. Quarterly Journal of Economics 106(1), 163-179.

Moro, A. and P. Norman (2004). A general equilibrium model of statistical discrimination. Journal of Economic Theory 114, 1-30. 
Oi, W. and T. Idson (1999). Firm size and wages. In O. Ashenfelter and D. Card (Eds.), Handbook of labor economics, Volume 3, pp. 2165-2215. North-Holland.

Pissarides, C. A. (2000). Equilibrium Unemployment Theory. MIT Press, Cambridge MA and London England.

Shi, S. (2002a). A directed search model of inequality with heterogeneous skills and skill-biased technology. Review of Economic Studies 69(2), 467-491.

Shi, S. (2002b). Product market and the size-wage differential. International Economic Review 43(1), 21-54.

Shimer, R. (2005). The assignment of workers to jobs in an economy with coordination frictions. Journal of Political Economy 113(5), 996-1025.

Spence, M. (1973). Job market signaling. Quarterly Journal of Economics 87, 355374.

Stigler, G. (1962). Information in the labor market. Journal of Political Economy 70, 94-105.

Stiglitz, J. E. (1975). The theory of screening, education and the distribution of income. American Economic Review 65(3), 283-300.

Stiglitz, J. E. (2000). The contributions of the economics of information to twentieth century economcis. Quarterly Journal of Economics 115(4), 1441-1478.

Troske, K. (1999). Evidence on the employer size-wage premium from workerestablishment matched data. The Review of Economics and Statistics 81(1), 15-26.

Varian, H. R. (1980). A model of sales. American Economic Review 70(4), 651-659.

\section{Appendix A}

Proof of Lemma 1. We analyze firm $k$ 's hiring problem, who wins the right to hire in the $k$-th round, facing a pool of workers of mass $R_{k-1}$. First, we need to decide the 
wage the firm has to post to win the right to hire in round $k$. Let $\alpha_{k}$ be the proportion of high type workers among the pool of workers to be hired in this round. When $k=1$, $\alpha_{1}=\alpha$. For firm $k$, it faces two distinct groups of workers, those it recognizes as high type, who has an average productivities of

$$
H_{k}=\frac{\alpha_{k} \beta}{\alpha_{k} \beta+\left(1-\alpha_{k}\right)(1-\beta)},
$$

and those it recognizes as low type, who has an average productivities of

$$
\underline{H}_{k}=\frac{\alpha_{k}(1-\beta)}{\alpha_{k}(1-\beta)+\left(1-\alpha_{k}\right) \beta} .
$$

Note that the equal profit condition implies that firm $k$ can not offer a wage $w_{k}<$ $\underline{H}_{k}$, since with $w_{k}<\underline{H}_{k}$, firm $k$ would hire all remaining workers in the applicant pool and earn a positive profit. The rest of the firms have no workers to hire, thus only make zero profit.

Next, offering $w_{k}=\underline{H}_{k}$ and hiring $\psi$ proportion of those it recognizes as low type can not be part of any equilibrium either. Note that in this case, firm $k$ would still hire every worker it recognizes as high type. Suppose firm $k$ also hires $\psi$ proportion of low types at $w_{k}$, it would get a total profit of

$$
\tilde{\Pi}_{k}=R_{k-1}\left[\alpha_{k} \beta+\left(1-\alpha_{k}\right)(1-\beta)\right]\left[\frac{\alpha_{k} \beta}{\alpha_{k} \beta+\left(1-\alpha_{k}\right)(1-\beta)}-\frac{\alpha_{k}(1-\beta)}{\alpha_{k}(1-\beta)+\left(1-\alpha_{k}\right) \beta}\right] .
$$

Following similar arguments, the firm $k+1$ that hires immediately after firm $k$ can at most get a profit of

$$
\tilde{\Pi}_{k+1}=R_{k-1}[\beta(1-\beta)]\left[\alpha_{k}-\frac{\alpha_{k}(1-\beta)^{2}}{\alpha_{k}(1-\beta)^{2}+\left(1-\alpha_{k}\right) \beta^{2}}\right],
$$

Which corresponds to the case that $\psi=0$ and firm $k+1$ makes a wage offer that equals to the average productivities of workers it labels as "l" (note that based on previous argument offering $w_{k+1}<\underline{H}_{k+1}$ is not possible). It follows that

$$
\frac{\tilde{\Pi}_{k}-\tilde{\Pi}_{k+1}}{R_{k-1}}=\alpha_{k}\left(1-\alpha_{k}\right)(2 \beta-1)\left[\frac{\alpha_{k}(1-\beta)^{3}+\left(1-\alpha_{k}\right) \beta^{3}}{\left[\alpha_{k}(1-\beta)+\left(1-\alpha_{k}\right) \beta\right]\left[\alpha_{k}(1-\beta)^{2}+\left(1-\alpha_{k}\right) \beta^{2}\right]}\right]>0 .
$$

That is, firm $k$ makes higher profit than firm $k+1$. This violates the equal profit condition. Thus, firm $k$ offers $w_{k}=\underline{H}_{k}$ can not be supported in any equilibrium either. 
Therefore, firm $k$ has to offer a wage $w_{k}>\underline{H}_{k}$. This makes firm $k$ not to hire any worker it recognizes as low type, as hiring them will incur loss for the firm.

Proof of Lemma 2. Let's consider the generic firm $k$ again. To make a positive profit, it must offer $w_{k}<H_{k}$. Profit maximization also requires firm $k$ to hire every worker it labels as " $h$ ". As the same argument applies to all firms, all participating firms will hire all workers they think are of high type when it is their turn to hire. The proportion of high type workers after firm $k$ hired in the remaining pool equals

$$
\alpha_{k+1}=\frac{\alpha(1-\beta)^{k}}{\alpha(1-\beta)^{k}+(1-\alpha) \beta^{k}},
$$

and the average productivity of those firm $k+1$ recognize as high type is

$$
H_{k+1}=\frac{\alpha(1-\beta)^{k} \beta}{\alpha(1-\beta)^{k} \beta+(1-\alpha) \beta^{k}(1-\beta)} .
$$

As $H_{k+1}$ goes to zero in the limit with $k$, for any $r>0$, there exists a $\underline{k}$ such that for all $k \geq \underline{k}, H_{k}<r$. Thus firms hiring after the $\underline{k}$-th round would make a loss as they must offer at least $r$ to attract any worker.

Therefore, in any equilibrium in which firms make positive profit, there could only be a finite number of active firms. This violates the equal profit condition because non-active firms make zero profit. Thus we conclude that all firms must make zero profit in any equilibrium.

Proof of Proposition 3. The uniqueness of such an equilibrium, if it exists, is guaranteed by the previous results, in particular, Lemma 6. Thus we only need to establish its existence.

Given other firms' strategies, we show that there is no incentive for any firm $k$ to deviate. First, firm $k$ has no incentive to hire earlier than the $k$-th round. For any $h \geq 0$, we have:

$$
\begin{aligned}
\Pi_{k}^{k-h}-\Pi_{k}^{k-h-1}= & \left(\Pi_{k}^{k-h}-\Pi_{k-h}^{k-h}\right)-\left(\Pi_{k}^{k-h-1}-\Pi_{k-h}^{k-h-1}\right) \\
& =\beta(1-\beta)^{k-h-1} \alpha\left(\psi_{k}-\psi_{k-h}\right)-\beta(1-\beta)^{k-h-2} \alpha\left(\psi_{k}-\psi_{k-h}\right)>0
\end{aligned}
$$


Next, firm $k$ has no incentives to hire later than the $k$-th round. For any $h \geq 0$, wages $w_{k+h}$ and $w_{k+h+1}$ are such that

$$
\begin{aligned}
\Pi_{k}^{k+h}-\Pi_{k}^{k+h+1}= & \left(\Pi_{k}^{k+h}-\Pi_{k+h+1}^{k+h}\right)-\left(\Pi_{k}^{k+h+1}-\Pi_{k+h+1}^{k+h+1}\right) \\
& =\beta(1-\beta)^{k+h-1} \alpha\left(\psi_{k}-\psi_{k+h+1}\right)-\beta(1-\beta)^{k+h} \alpha\left(\psi_{k}-\psi_{k+h+1}\right)>0
\end{aligned}
$$

Given our previous discussions, firm $k$ hires $\beta(1-\beta)^{k-1} \alpha$ high type workers and $(1-\beta) \beta^{k-1}(1-\alpha)$ low type workers. The only exception is that for firm $K$, if condition (4) holds, firm $K$ makes zero profit, thus it could hire $\delta \beta(1-\beta)^{K-1} \alpha$ high type workers and $\delta(1-\beta) \beta^{K-1}(1-\alpha)$ low type workers in which $0<\delta \leq 1$. (f) simply follows from (c) and (d).

Proof of Proposition 4. We prove the result with Lemma A1 to Lemma A4.

Lemma A1. In any equilibrium, no firm hires all remaining workers when it wins the right to hire.

Proof. We show this by contradiction. Suppose firm $j$ hires all workers at round $k$ at wage $w_{k}$, then there must be some firms end up being inactive. Also, it must be that $w_{k}=\alpha_{k}$, the average productivities of the applicant pool, such that firm $j$ only breaks even. Otherwise an inactive firm could bid $w_{k}+\epsilon$, hire all workers at round $k$, and make strictly positive profit.

In this case, an inactive firm could deviate by offering $w_{k}+\epsilon$ at round $k$. It could then hire all workers it labels as " $h$ " and make a strictly positive profit, as the average productivities of those workers will be greater than $\alpha_{k}$.

Lemma A2. In any equilibrium, profits of active firms strictly increase in their $\beta$. That is, for two firms $i$ and $j$ that both hire a positive measure of workers, $\beta_{i}>\beta_{j}$ implies $\Pi_{i}>\Pi_{j}$.

Proof. Without loss of generality, suppose there is an equilibrium in which firm $j$ hires in the $k$-th round from an applicant pool with $\tilde{n}_{k}$ measure of high type workers and 
$\tilde{m}_{k}$ measure of low type workers, at a wage $w_{k}$. Suppose firm $j$ hires $\bar{\delta}_{k}>0$ proportion of workers it labels as " $h$ ", and hires $\underline{\delta}_{k}$ proportion of those it labels as "l".

Based on Lemma A1, it must be that profits from "l" workers are zero even when those workers are hired. Thus, firm j's total profit is

$$
\Pi_{j}^{k}=\bar{\delta}_{k} \tilde{n}_{k} \beta_{j}-\bar{\delta}_{k}\left[\tilde{n}_{k} \beta_{j}+\tilde{m}_{k}\left(1-\beta_{j}\right)\right] w_{k} \geq 0
$$

As $\beta_{i}>\beta_{j}$, it can be shown that

$$
\tilde{n}_{k} \beta_{i}-\left[\tilde{n}_{k} \beta_{i}+\tilde{m}_{k}\left(1-\beta_{i}\right)\right] w_{k}>\tilde{n}_{k} \beta_{j}-\left[\tilde{n}_{k} \beta_{j}+\tilde{m}_{k}\left(1-\beta_{j}\right)\right] w_{k} \geq 0 .
$$

This is because $\tilde{n}_{k} \geq \tilde{n}_{k} w_{k}+\tilde{m}_{k} w_{k} \frac{1-\beta_{j}}{\beta_{j}}>\tilde{n}_{k} w_{k}>\tilde{n}_{k} w_{k}-\tilde{m}_{k} w_{k}$.

Therefore, in equilibrium firm $i$ could at least offer $w_{k}$ at the $k$-th round and hire all workers it labels as “ $h$ ”. Hence

$$
\Pi_{i} \geq \Pi_{i}^{k}=\tilde{n}_{k} \beta_{j}-\left[\tilde{n}_{k} \beta_{j}+\tilde{m}_{k}\left(1-\beta_{j}\right)\right] w_{k}>\Pi_{j}^{k},
$$

and firm $i$ earns a higher profit than firm $j$ in equilibrium.

Lemma A3. In any equilibrium, number of active firms $K$ is finite. In addition, all active firms except the one with worst information among them (which is firm K) hire all workers they label as " $h$ ". No active firm hires any worker it labels as "l”.

Proof. Following Lemma A2, all active firms except the one with lowest $\beta$ must earn strictly positive profit. Thus to maximize profit, it is necessary for them to hire all " $h$ " workers given the wage offers. This ensures that worker average productivity strictly deteriorates each round (except for maybe when firm $K$ hires). As reservation wage $r$ is positive, number of active firms $K$ must be finite.

To see why firms don't hire "l" workers, note that in any round it is necessary that wage $w_{k}$ is greater than the average productivity of all workers $\alpha_{k}$, otherwise an inactive firm can enter by offering $w_{k}+\epsilon$ and earn a positive profit by hiring all workers. As the average productivity of workers the firm recognizes as low type is strictly less than $\alpha_{k}$, it is not profitable for the firm to hire any one of them at $w_{k}$.

Lemma A4. Wage offers strictly decrease in any equilibrium. That is, for any consecutive rounds $k$ and $k+1, w_{k}>w_{k+1}$. 
Proof. We prove this by contradiction. Suppose $w_{k} \leq w_{k+1}$. Let the applicant pool for the $k$-th round consists of $\tilde{n}_{k}$ measure of high type and $\tilde{m}_{k}$ measure of low type workers. Let firms $i$ and $j$ hire in the $k$-th and $(k+1)$-th rounds, respectively. Firm $j$ 's profit from hiring in the $(k+1)$-th round equals

$$
\Pi_{j}^{k+1}=\tilde{n}_{k}\left(1-\beta_{i}\right) \beta_{j}-\left[\tilde{n}_{k}\left(1-\beta_{i}\right) \beta_{j}+\tilde{m}_{k} \beta_{i}\left(1-\beta_{j}\right)\right] w_{k+1} .
$$

As $w_{k} \leq w_{k+1}$, it can shown that firm $j$ would deviate to hire in the $k$-th round at $w_{k}+\epsilon$ and earn a higher level of profit.

$$
\Pi_{j}^{k}=\tilde{n}_{k} \beta_{j}-\left[\tilde{n}_{k} \beta_{j}+\tilde{m}_{k}\left(1-\beta_{j}\right]\left(w_{k}+\epsilon\right)>\Pi_{j}^{k+1} .\right.
$$

This is because $\frac{\Pi_{j}^{k}-\Pi_{j}^{k+1}}{\beta_{j}} \geq \tilde{n}_{k} \beta_{i}-\left[\tilde{n}_{k} \beta_{i}+\tilde{m}_{k}\left(1-\beta_{i}\right) \frac{1-\beta_{j}}{\beta_{j}}\right] w_{k}>\Pi_{i}^{k}>0$. Hence, there exists no equilibrium such that $w_{k} \leq w_{k+1}$.

Proof of Lemma 7. We prove this by contradiction, supposing firm $i$ hires in the $k$-th round and firm $j$ hires in the $k+1$-th round, with $\beta_{i}<(>) \beta_{j}$ (note that by assumption no two $\beta$ s are equal).

Note that firm $i$ 's profit is $\Pi_{i}^{k}=\tilde{n}_{k} \beta_{i}-\left[\tilde{n}_{k} \beta_{i}+\tilde{m}_{k}\left(1-\beta_{i}\right)\right] w_{k}$ and firm $j$ 's profit is $\Pi_{j}^{k+1}=\tilde{n}_{k}\left(1-\beta_{i}\right) \beta_{j}-\left[\tilde{n}_{k}\left(1-\beta_{i}\right) \beta_{j}+m_{k} \beta_{i}\left(1-\beta_{j}\right)\right] w_{k+1}$. Consider the possible deviating case where firm $j$ hires in the $k$-th round at $w_{k}$ and firm $i$ hires in the $k+1$-th round at $w_{k+1}$, then it must be that $\Pi_{i}^{k} \geq \Pi_{i}^{k+1}$ and $\Pi_{j}^{k} \leq \Pi_{j}^{k+1}$ in order for the equilibrium to hold.

However, note that $\left(\Pi_{i}^{k}-\Pi_{i}^{k+1}\right)-\left(\Pi_{j}^{k}-\Pi_{j}^{k+1}\right)=\left(\Pi_{i}^{k}-\Pi_{j}^{k}\right)-\left(\Pi_{i}^{k+1}-\Pi_{j}^{k+1}\right)=\left(\beta_{i}-\right.$ $\left.\beta_{j}\right)\left(\tilde{n}_{k}-\tilde{m}_{k}\right)\left(w_{k+1}-w_{k}\right)<0$, as $\beta_{i}<(>) \beta_{j}, \tilde{n}_{k}<(>) \tilde{m}_{k}$ and $w_{k+1}<w_{k}$ (Lemma A4). In equilibrium, by backward induction, $w_{k}$ is determined such that $\Pi_{j}^{k}=\Pi_{j}^{k+1}$. Therefore, we have $\Pi_{i}^{k}<\Pi_{i}^{k+1}$, and there is a contradiction.

Proof of Proposition 5. We first prove the existence of the equilibrium, i.e., for any active firm $k$, hiring in the $k$-th round is its best response when all other firms are hiring in the order of $\beta$. Note that when only one firm deviate in the order of hiring, the sequence of wages stay unchanged. 
First, we show that firm $k$ has no incentives to hire one round later, i.e., $\Pi_{k}^{k} \geq \Pi_{k}^{k+1}$. To see this, let there be $\tilde{n}_{k}$ measure of high type and $\tilde{m}_{k}$ measure of low type workers at the beginning of round $k$. Thus,

$$
\Pi_{k}^{k}=\tilde{n}_{k} \beta_{k}-\left[\tilde{n}_{k} \beta_{k}+\tilde{m}_{k}\left(1-\beta_{k}\right)\right] w_{k} .
$$

While if firm $k$ deviates to round $k+1$,

$$
\Pi_{k}^{k+1}=\tilde{n}_{k}\left(1-\beta_{k+1}\right) \beta_{k}-\left[\tilde{n}_{k}\left(1-\beta_{k+1}\right) \beta_{k}+\tilde{m}_{k} \beta_{k+1}\left(1-\beta_{k}\right)\right] w_{k+1} .
$$

Similarly, we have that $\Pi_{k+1}^{k}=\tilde{n}_{k} \beta_{k+1}-\left[\tilde{n}_{k} \beta_{k+1}+\tilde{m}_{k}\left(1-\beta_{k+1}\right)\right] w_{k}$ and $\Pi_{k+1}^{k+1}=$ $\tilde{n}_{k}\left(1-\beta_{k}\right) \beta_{k+1}-\left[\tilde{n}_{k}\left(1-\beta_{k}\right) \beta_{k+1}+\tilde{m}_{k} \beta_{k}\left(1-\beta_{k+1}\right)\right] w_{k+1}$.

$$
\Pi_{k}^{k}-\Pi_{k}^{k+1}=\left[\Pi_{k}^{k}-\Pi_{k+1}^{k}\right]-\left[\Pi_{k}^{k+1}-\Pi_{k+1}^{k+1}\right]=\left(\beta_{k}-\beta_{k+1}\right)\left(\tilde{m}_{k}-\tilde{n}_{k}\right)\left(w_{k}-w_{k+1}\right)>0 .
$$

The first equality follows because $\Pi_{k+1}^{k}=\Pi_{k+1}^{k+1}$. The last inequality follows because $\alpha<1 / 2$ ensures that $\tilde{m}_{k}>\tilde{n}_{k}$ for any $k$. Also, $\beta_{k}>\beta_{k+1}$ and $w_{k}>w_{k+1}$ (Lemma A4).

We then show that firm $k$ also has no incentive to wait in further later later rounds, i.e, $\Pi_{k}^{h} \geq \Pi_{k}^{h+1}$ for any $h>k$.

$$
\begin{aligned}
\prod_{k}^{h}= & \alpha \frac{\beta_{k}}{1-\beta_{k}} \prod_{i=1}^{h}\left(1-\beta_{i}\right)-\left[\alpha \frac{\beta_{k}}{1-\beta_{k}} \prod_{i=1}^{h}\left(1-\beta_{i}\right)\right. \\
& \left.+(1-\alpha) \frac{\left(1-\beta_{k}\right)}{\beta_{k}} \prod_{i=1}^{h} \beta_{i}\right] w_{h} .
\end{aligned}
$$

Alternatively, if firm $k$ hires in the $(h+1)$-th round, its profit would be

$$
\begin{aligned}
\Pi_{k}^{h+1}= & \alpha \frac{\beta_{k}}{1-\beta_{k}} \prod_{i=1}^{h+1}\left(1-\beta_{i}\right)-\left[\alpha \frac{\beta_{k}}{1-\beta_{k}} \prod_{i=1}^{h+1}\left(1-\beta_{i}\right)\right. \\
& \left.+(1-\alpha) \frac{\left(1-\beta_{k}\right)}{\beta_{k}} \prod_{i=1}^{h+1} \beta_{i}\right] w_{h+1} .
\end{aligned}
$$

Define $A=\frac{\alpha}{1-\beta_{k}} \prod_{i=1}^{h-1}\left(1-\beta_{i}\right)$ and $B=\frac{(1-\alpha)}{\beta_{k}} \prod_{i=1}^{h-1} \beta_{i}$, we have:

$$
\begin{aligned}
& \Pi_{k}^{h}-\Pi_{k}^{h+1}=\beta_{k}\left(1-\beta_{h}\right) \beta_{h+1} A-\beta_{k}\left(1-\beta_{h}\right) A\left[w_{h}-\left(1-\beta_{h+1}\right) w_{h+1}\right] \\
& -\left(1-\beta_{k}\right) \beta_{h} B\left[w_{h}-\beta_{h+1} w_{h+1}\right] .
\end{aligned}
$$


From previous discussions, we know that wages $w_{h}$ and $w_{h+1}$ are determined such that $\Pi_{h+1}^{h}=\Pi_{h+1}^{h+1}$, where

$$
\Pi_{h+1}^{h}=\alpha \beta_{h+1} \prod_{i=1}^{h-1}\left(1-\beta_{i}\right)-\left[\alpha \beta_{h+1} \prod_{i=1}^{h-1}\left(1-\beta_{i}\right)+(1-\alpha)\left(1-\beta_{h+1}\right) \prod_{i=1}^{h-1} \beta_{i}\right] w_{h}
$$

and

$$
\Pi_{h+1}^{h+1}=\alpha \beta_{h+1} \prod_{i=1}^{h}\left(1-\beta_{i}\right)-\left[\alpha \beta_{h+1} \prod_{i=1}^{h}\left(1-\beta_{i}\right)+(1-\alpha)\left(1-\beta_{h+1}\right) \prod_{i=1}^{h} \beta_{i}\right] w_{h+1} .
$$

Note that

$$
\begin{aligned}
\Pi_{h+1}^{h}-\Pi_{h+1}^{h+1}= & \beta_{h+1} \beta_{h}\left(1-\beta_{k}\right) A-\beta_{h+1}\left(1-\beta_{k}\right) A\left[w_{h}-\left(1-\beta_{h}\right) w_{h+1}\right] \\
& -\left(1-\beta_{h+1}\right) \beta_{k} B\left[w_{h}-\beta_{h} w_{h+1}\right] .
\end{aligned}
$$

Thus,

$$
\begin{aligned}
& \Pi_{k}^{h}-\Pi_{k}^{h+1}=\Pi_{k}^{h}-\Pi_{k}^{h+1}-\left[\Pi_{h+1}^{h}-\Pi_{h+1}^{h+1}\right] \\
& =A\left[\beta_{h+1}\left(\beta_{k}-\beta_{h}\right)-\left(\beta_{k}\left(1-\beta_{h}\right)-\beta_{h+1}\left(1-\beta_{k}\right)\right) w_{h}+\left(\beta_{k}\left(1-\beta_{h}\right)\left(1-\beta_{h+1}\right)\right.\right. \\
& \left.\left.-\left(1-\beta_{h}\right) \beta_{h+1}\left(1-\beta_{k}\right)\right) w_{h+1}\right] \\
& +B\left[\left(\left(1-\beta_{h+1}\right) \beta_{k}-\beta_{h}\left(1-\beta_{k}\right)\right) w_{h}-\left(\left(1-\beta_{h+1}\right) \beta_{h} \beta_{k}-\beta_{h}\left(1-\beta_{k}\right) \beta_{h+1}\right) w_{h+1}\right] .
\end{aligned}
$$

Note that $\alpha<1 / 2, \beta_{i}>1 / 2$ for all $i$ and $h>k$ imply $A<B$. Also, because $\beta_{k}>\beta_{h}$ and $\beta_{h+1}<1$, we have $\left(1-\beta_{h+1}\right) \beta_{k}-\beta_{h}\left(1-\beta_{k}\right)>\left(1-\beta_{h+1}\right) \beta_{h} \beta_{k}-\beta_{h}\left(1-\beta_{k}\right) \beta_{h+1}$, which together with the condition that $w_{h}>w_{h+1}$ (Lemma A4) ensures the last term of the above equation is non-negative. Thus,

$$
\begin{aligned}
& \Pi_{k}^{h}-\Pi_{k}^{h+1} \\
& \geq A\left[\beta_{h+1}\left(\beta_{k}-\beta_{h}\right)-\left(\beta_{k}\left(1-\beta_{h}\right)-\beta_{h+1}\left(1-\beta_{k}\right)\right) w_{h}+\left(\beta_{k}\left(1-\beta_{h}\right)\left(1-\beta_{h+1}\right)\right.\right. \\
& \left.\left.-\left(1-\beta_{h}\right) \beta_{h+1}\left(1-\beta_{k}\right)\right) w_{h+1}\right] \\
& +A\left[\left(\left(1-\beta_{h+1}\right) \beta_{k}-\beta_{h}\left(1-\beta_{k}\right)\right) w_{h}-\left(\left(1-\beta_{h+1}\right) \beta_{h} \beta_{k}-\beta_{h}\left(1-\beta_{k}\right) \beta_{h+1}\right) w_{h+1}\right] \\
& =A\left[\beta_{h+1}\left(\beta_{k}-\beta_{h}\right)+\left(2 \beta_{k}-1\right)\left(\beta_{h}-\beta_{h+1}\right) w_{h}-\left(2 \beta_{h}-1\right)\left(\beta_{k}-\beta_{h+1}\right) w_{h+1}\right] \\
& >A\left[\beta_{h+1}\left(\beta_{k}-\beta_{h}\right)+\left(2 \beta_{k}-1\right)\left(\beta_{h}-\beta_{h+1}\right) w_{h}-\left(2 \beta_{h}-1\right)\left(\beta_{k}-\beta_{h+1}\right) w_{h}\right] \\
& =A\left[\beta_{h+1}\left(\beta_{k}-\beta_{h}\right)-\left(2 \beta_{h+1}-1\right)\left(\beta_{k}-\beta_{h}\right) w_{h}\right]>0 .
\end{aligned}
$$


The last inequality holds as $w_{h}<1$ and $\beta_{h+1}<1$.

Next, we consider firm $k$ 's $(k \geq 2)$ incentive to hire in earlier rounds. Note that for any $\tau \leq k$, firm $k$ 's profit to hire in the $\tau$-th round would be

$$
\Pi_{k}^{\tau}=\alpha \beta_{k} \prod_{i=1}^{\tau-1}\left(1-\beta_{i}\right)-\left[\alpha \beta_{k} \prod_{i=1}^{\tau-1}\left(1-\beta_{i}\right)+(1-\alpha)\left(1-\beta_{k}\right) \prod_{i=1}^{\tau-1} \beta_{i}\right] w_{\tau},
$$

while the profit for firm $k$ to hire in the $\tau-1$-th round would be

$$
\Pi_{k}^{\tau-1}=\alpha \beta_{k} \prod_{i=1}^{\tau-2}\left(1-\beta_{i}\right)-\left[\alpha \beta_{k} \prod_{i=1}^{\tau-2}\left(1-\beta_{i}\right)+(1-\alpha)\left(1-\beta_{k}\right) \prod_{i=1}^{\tau-2} \beta_{i}\right] w_{\tau-1} .
$$

Taking the difference of the two profit functions gives

$$
\begin{aligned}
\Pi_{k}^{\tau}-\Pi_{k}^{\tau-1}= & \beta_{k}\left\{-\alpha \beta_{\tau-1} \prod_{i=1}^{\tau-2}\left(1-\beta_{i}\right)+\alpha \prod_{i=1}^{\tau-2}\left(1-\beta_{i}\right)\left[w_{\tau-1}-\left(1-\beta_{\tau-1}\right) w_{\tau}\right]\right. \\
& \left.+(1-\alpha) \frac{1-\beta_{k}}{\beta_{k}} \prod_{i=1}^{\tau-2} \beta_{i}\left[w_{\tau-1}-\beta_{\tau-1} w_{\tau}\right]\right\} .
\end{aligned}
$$

The condition $\Pi_{\tau}^{\tau-1}=\Pi_{\tau}^{\tau}$ implies

$$
\begin{aligned}
& \beta_{\tau}\left\{-\alpha \beta_{\tau-1} \prod_{i=1}^{\tau-2}\left(1-\beta_{i}\right)+\alpha \prod_{i=1}^{\tau-2}\left(1-\beta_{i}\right)\left[w_{\tau-1}-\left(1-\beta_{\tau-1}\right) w_{\tau}\right]\right. \\
& \left.+(1-\alpha) \frac{1-\beta_{\tau}}{\beta_{\tau}} \prod_{i=1}^{\tau-2} \beta_{i}\left[w_{\tau-1}-\beta_{\tau-1} w_{\tau}\right]\right\}=0 .
\end{aligned}
$$

For $\tau<k$, because $\beta_{k}<\beta_{\tau},\left(1-\beta_{k}\right) / \beta_{k}>\left(1-\beta_{\tau}\right) / \beta_{\tau}$. Hence, (A.1) implies $\Pi_{k}^{\tau}>\Pi_{k}^{\tau-1}$. When $\tau=k$, this shows that $\Pi_{k}^{k}=\Pi_{k}^{k-1}$. Therefore, firm $k$ has no incentive to hire in earlier rounds.

The uniqueness of the equilibrium follows naturally from Lemma 7, as there are always less high type workers than low type workers in each round, no other order of hiring can exist.

Also, given the order of hiring, firm $K$ hires $\alpha \prod_{i=1}^{K-1}\left(1-\beta_{i}\right) \beta_{K}$ measure of high type workers and $(1-\alpha) \prod_{i=1}^{K-1} \beta_{i}\left(1-\beta_{K}\right)$ low type workers. As firm $K$ has to break even, it is necessary that $\frac{\alpha \prod_{i=1}^{K-1}\left(1-\beta_{i}\right) \beta_{K}}{\alpha \prod_{i=1}^{K-1}\left(1-\beta_{i}\right) \beta_{K}+(1-\alpha) \prod_{i=1}^{K-1} \beta_{i}\left(1-\beta_{K}\right)} \geq r$. Also, firm $K+1$ and all other firms with lower $\beta$ are not able to pay at least the reservation wage to hire anyone from the pool of unemployed workers, thus $\frac{\alpha \prod_{i=1}^{K}\left(1-\beta_{i}\right) \beta_{K+1}}{\alpha \prod_{i=1}^{K}\left(1-\beta_{i}\right) \beta_{K+1}+(1-\alpha) \prod_{i=1}^{K} \beta_{i}\left(1-\beta_{K+1}\right)} \geq r$. These two conditions collectively determine number of active firms $K$. 
Note that firm $K$ is paying a wage of

$$
w_{K}=\max \left\{r, \frac{\alpha\left[\prod_{i=1}^{K-1}\left(1-\beta_{k}\right)\right] \beta_{K}}{\alpha\left[\prod_{i=1}^{K-1}\left(1-\beta_{k}\right)\right] \beta_{K}+(1-\alpha)\left[\prod_{i=1}^{K-1} \beta_{k}\right]\left(1-\beta_{K}\right)}\right\},
$$

Other wages are determined recursively using $\Pi_{k}^{k}=\Pi_{k}^{k-1}$.

Proof of Corollary 2. The measure of workers at firm $k$ is

$$
N_{k}=\alpha \beta_{k} \prod_{i=1}^{k-1}\left(1-\beta_{i}\right)+(1-\alpha)\left(1-\beta_{k}\right) \prod_{i=1}^{k-1} \beta_{i}
$$

while the measure of workers at firm $k+1$ is

$$
N_{k+1}=\alpha \beta_{k+1} \prod_{i=1}^{k}\left(1-\beta_{i}\right)+(1-\alpha)\left(1-\beta_{k+1}\right) \prod_{i=1}^{k} \beta_{i} .
$$

Note that the difference equals

$$
\begin{aligned}
N_{k}-N_{k+1} & =\left(\beta_{k}-\beta_{k+1}+\beta_{k} \beta_{k+1}\right) \alpha \prod_{i=1}^{k-1}\left(1-\beta_{i}\right)+\left(1+\beta_{k} \beta_{k+1}-2 \beta_{k}\right)(1-\alpha) \prod_{i=1}^{k-1} \beta_{i} \\
& =\alpha \prod_{i=1}^{k-1}\left(1-\beta_{i}\right)\left\{\left(\beta_{k}-\beta_{k+1}+\beta_{k} \beta_{k+1}\right)+\left(1+\beta_{k} \beta_{k+1}-2 \beta_{k}\right) \frac{(1-\alpha)}{\alpha} \prod_{i=1}^{k-1} \frac{\beta_{i}}{1-\beta_{i}}\right\} .
\end{aligned}
$$

Note that $\beta_{k}-\beta_{k+1}+\beta_{k} \beta_{k+1}>0$ as $\beta_{k}>\beta_{k+1}$ and $1 / 2<\beta_{k}<1$. Therefore, under the condition that $\left(1-\beta_{k}\right) /\left(1-\beta_{k+1}\right) \geq \beta_{k}, N_{k}-N_{k+1}>0$, which implies that the measure of workers decreases in the order of hiring. Because wages also decrease in the order of hiring (Lemma A4), there is a positive relationship between firm size and wage.

Proof of Proposition 6. We prove the result in two steps. First, we need to show that firms $1,3,4, \ldots, K$ have no incentives to deviate. Note that at the beginning of the second round, we have $\alpha_{2} \leq 1 / 2$ as $\alpha \leq \beta_{2}$, thus the subgame after firm 2 has hired is an equilibrium as we have analyzed before. We only need to show that firms $1,3,4, \ldots, K$ have no incentives to deviate to the first round. This is trivial for firm 1 as it is indifferent between hiring in the first round and the second round, $\Pi_{1}^{2}=\Pi_{1}^{1}$.

For firm $k \geq 3$, the same proof in Proposition 5 would suggest that $\Pi_{k}^{2} \leq \Pi_{k}^{k}$, i.e., firm $k$ has no incentive to deviate to the second round. Thus we only need to show that $\Pi_{k}^{2}-\Pi_{k}^{1}>0$. Note

$$
\Pi_{k}^{2}-\Pi_{k}^{1}=\beta_{k}\left\{-\alpha \beta_{2}+\alpha\left[w_{1}-\left(1-\beta_{2}\right) w_{2}\right]+(1-\alpha) \frac{1-\beta_{k}}{\beta_{k}}\left[w_{1}-\beta_{2} w_{2}\right]\right\} .
$$


Since $\left(1-\beta_{1}\right) / \beta_{1}<\left(1-\beta_{k}\right) / \beta_{k}$, the condition

$$
\Pi_{1}^{2}-\Pi_{1}^{1}=\beta_{1}\left\{-\alpha \beta_{2}+\alpha\left[w_{1}-\left(1-\beta_{2}\right) w_{2}\right]+(1-\alpha) \frac{1-\beta_{1}}{\beta_{1}}\left[w_{1}-\beta_{2} w_{2}\right]\right\}=0 .
$$

implies that $\Pi_{k}^{2}-\Pi_{k}^{1}>0$.

Next, we show that firm 2 has no incentives to deviate to later rounds, i.e., $\Pi_{2}^{1} \geq \Pi_{2}^{h}$ for $h \geq 2$. To see that firm 2 has no incentive to deviate to the second round, note that $\Pi_{2}^{1}-\Pi_{2}^{2}=\left(\Pi_{2}^{1}-\Pi_{1}^{1}\right)-\left(\Pi_{2}^{2}-\Pi_{1}^{2}\right)=(2 \alpha-1)\left(\beta_{1}-\beta_{2}\right)\left(w_{1}-w_{2}\right)>0$. Thus, we only need to show $\Pi_{2}^{h}>\Pi_{2}^{h+1}$ for $h \geq 2$.

The profits for firm 2 to hire in the $h$-th and the $(h+1)$-th round are, respectively,

$$
\begin{gathered}
\Pi_{2}^{h}=\alpha \beta_{2}\left(1-\beta_{1}\right) \prod_{i=3}^{h}\left(1-\beta_{i}\right)-\left[\alpha \beta_{2}\left(1-\beta_{1}\right) \prod_{i=3}^{h}\left(1-\beta_{i}\right)+(1-\alpha) \beta_{1}\left(1-\beta_{2}\right) \prod_{i=3}^{h} \beta_{i}\right] w_{h}, \\
\Pi_{2}^{h+1}=\alpha \beta_{2}\left(1-\beta_{1}\right) \prod_{i=3}^{h+1}\left(1-\beta_{i}\right)-\left[\alpha \beta_{2}\left(1-\beta_{1}\right) \prod_{i=3}^{h+1}\left(1-\beta_{i}\right)+(1-\alpha) \beta_{1}\left(1-\beta_{2}\right) \prod_{i=3}^{h+1} \beta_{i}\right] w_{h+1} .
\end{gathered}
$$

Taking differences, we have

$$
\begin{aligned}
& \Pi_{2}^{h}-\Pi_{2}^{h+1}=\alpha \beta_{2} \beta_{h+1}\left(1-\beta_{1}\right) \prod_{i=3}^{h}\left(1-\beta_{i}\right)-\alpha \beta_{2}\left(1-\beta_{1}\right) \prod_{i=3}^{h}\left(1-\beta_{i}\right)\left[w_{h}-\left(1-\beta_{h+1}\right) w_{h+1}\right] \\
& -(1-\alpha) \beta_{1}\left(1-\beta_{2}\right) \prod_{i=3}^{h} \beta_{i}\left[w_{h}-\beta_{h+1} w_{h+1}\right] .
\end{aligned}
$$

Note that $\Pi_{h+1}^{h}=\Pi_{h+1}^{h+1}$ implies

$$
\begin{aligned}
& \alpha \beta_{h} \beta_{h+1} \prod_{i=1}^{2}\left(1-\beta_{i}\right) \prod_{j=3}^{h-1}\left(1-\beta_{j}\right)-\alpha \beta_{h+1} \prod_{i=1}^{2}\left(1-\beta_{i}\right) \prod_{j=3}^{h-1}\left(1-\beta_{j}\right)\left[w_{h}-\left(1-\beta_{h}\right) w_{h+1}\right] \\
& -(1-\alpha)\left(1-\beta_{h+1}\right) \prod_{i=1}^{2} \beta_{i} \prod_{j=3}^{h-1} \beta_{j}\left[w_{h}-\beta_{h} w_{h+1}\right]=0 .
\end{aligned}
$$

Therefore,

$$
\begin{aligned}
& \Pi_{2}^{h}-\Pi_{2}^{h+1}=\Pi_{2}^{h}-\Pi_{2}^{h+1}-\left(\Pi_{h+1}^{h}-\Pi_{h+1}^{h+1}\right) \\
& =\alpha\left(1-\beta_{1}\right) \prod_{i=3}^{h-1}\left(1-\beta_{i}\right)\left[\beta_{h+1}\left(\beta_{2}-\beta_{h}\right)-\left(\beta_{2}\left(1-\beta_{h}\right)-\beta_{h+1}\left(1-\beta_{2}\right)\right) w_{h}+\left(\beta_{2}-\beta_{h+1}\right)\left(1-\beta_{h}\right) w_{h+1}\right]+ \\
& (1-\alpha) \beta_{1} \prod_{i=3}^{h-1} \beta_{i}\left[\left(\beta_{2}\left(1-\beta_{h+1}\right)-\beta_{h}\left(1-\beta_{2}\right)\right) w_{h}-\beta_{h}\left(\beta_{2}-\beta_{h+1}\right) w_{h+1}\right]
\end{aligned}
$$


Note that $\beta_{2}>\beta_{h}, \beta_{h+1}<1$ and $w_{h}>w_{h+1}$ implies that $\left(\beta_{2}\left(1-\beta_{h+1}\right)-\beta_{h}(1-\right.$ $\left.\left.\beta_{2}\right)\right) w_{h}-\beta_{h}\left(\beta_{2}-\beta_{h+1}\right) w_{h+1}>0$. In addition, $\beta_{2} \geq \alpha$ implies $\alpha\left(1-\beta_{1}\right) \prod_{i=3}^{h-1}\left(1-\beta_{i}\right) \leq$ $(1-\alpha) \beta_{1} \prod_{i=3}^{h-1} \beta_{i}$. Thus,

$$
\begin{aligned}
& \Pi_{2}^{h}-\Pi_{2}^{h+1} \\
& \geq \alpha\left(1-\beta_{1}\right) \prod_{i=3}^{h-1}\left(1-\beta_{i}\right)\left[\beta_{h+1}\left(\beta_{2}-\beta_{h}\right)-\left(\beta_{2}\left(1-\beta_{h}\right)-\beta_{h+1}\left(1-\beta_{2}\right)\right) w_{h}+\left(\beta_{2}-\beta_{h+1}\right)\left(1-\beta_{h}\right) w_{h+1}\right]+ \\
& \alpha\left(1-\beta_{1}\right) \prod_{i=3}^{h-1}\left[\left(\beta_{2}\left(1-\beta_{h+1}\right)-\beta_{h}\left(1-\beta_{2}\right)\right) w_{h}-\beta_{h}\left(\beta_{2}-\beta_{h+1}\right) w_{h+1}\right] \\
& =\alpha\left(1-\beta_{1}\right) \prod_{j=3}^{h-1}\left(1-\beta_{i}\right)\left\{\beta_{h+1}\left(\beta_{2}-\beta_{h}\right)+\left[\left(2 \beta_{2}-1\right)\left(\beta_{h}-\beta_{h+1}\right) w_{h}\right]-\left(2 \beta_{h}-1\right)\left(\beta_{2}-\beta_{h+1}\right) w_{h+1}\right\} \\
& >\alpha\left(1-\beta_{1}\right) \prod_{j=3}^{h-1}\left(1-\beta_{i}\right)\left\{\beta_{h+1}\left(\beta_{2}-\beta_{h}\right)+\left[\left(2 \beta_{2}-1\right)\left(\beta_{h}-\beta_{h+1}\right) w_{h}\right]-\left(2 \beta_{h}-1\right)\left(\beta_{2}-\beta_{h+1}\right) w_{h}\right\} \\
& >\alpha\left(1-\beta_{1}\right) \prod_{j=3}^{h-1}\left(1-\beta_{i}\right)\left\{\beta_{h+1}\left(\beta_{2}-\beta_{h}\right)-\left[\left(2 \beta_{h+1}-1\right)\left(\beta_{2}-\beta_{h}\right) w_{h}\right]\right\} \\
& >\alpha\left(1-\beta_{1}\right) \prod_{j=3}^{h-1}\left(1-\beta_{i}\right)\left\{\beta_{h+1}\left(\beta_{2}-\beta_{h}\right)-\left[\left(2 \beta_{h+1}-1\right)\left(\beta_{2}-\beta_{h}\right)\right]\right\} \\
& =\alpha\left(1-\beta_{1}\right) \prod_{j=3}^{h-1}\left(1-\beta_{i}\right)\left[\left(\beta_{2}-\beta_{h}\right)\left(1-\beta_{h+1}\right)\right]>0 .
\end{aligned}
$$

This concludes the proof that the aforementioned equilibrium is indeed an equilibrium. The uniqueness follows from the proof of Proposition 5 and also Lemma 7. Also, the number of active firms $K$ is determined by condition (5).

Proof of Proposition 7. We demonstrate the result in two steps. First, let the firms hiring in the first three rounds be $i, j$ and $k$, respectively. Note that since $\alpha>1 / 2$, firm 1 cannot be the one hiring in the first round. Any firm other than firm 1 hiring in the first round would lead to $\alpha_{2}>1 / 2$ as $\alpha>\beta_{2}$. Therefore, we know that $\beta_{i}<\beta_{j}<\beta_{k}$ based on Lemma 7.

Next, we show the above hiring order cannot be an equilibrium. Suppose it is, then we have $\Pi_{k}^{3}=\Pi_{k}^{2}$, and $\Pi_{j}^{2}=\Pi_{j}^{1}$. But the two indifference conditions would imply $\Pi_{k}^{1}>$ $\Pi_{k}^{3}$, i.e., firm $k$ strictly prefers to hire in the first round. To see this, note that the indif- 
ference condition $\Pi_{j}^{1}-\Pi_{j}^{2}=\beta_{j}\left\{\alpha \beta_{i}-\alpha\left[w_{1}-\left(1-\beta_{i}\right) w_{2}\right]-(1-\alpha) \frac{1-\beta_{j}}{\beta_{j}}\left[w_{1}-\beta_{i} w_{2}\right]\right\}=0$ indicates

$$
\Pi_{k}^{1}-\Pi_{k}^{3}=\Pi_{k}^{1}-\Pi_{k}^{2}=\beta_{k}\left\{\alpha \beta_{i}-\alpha\left[w_{1}-\left(1-\beta_{i}\right) w_{2}\right]-(1-\alpha) \frac{1-\beta_{k}}{\beta_{k}}\left[w_{1}-\beta_{i} w_{2}\right]\right\}>0,
$$

as $\left(1-\beta_{j}\right) / \beta_{j}<\left(1-\beta_{k}\right) / \beta_{k}$.

Lemma A5. When $\alpha=1 / 2$, there exists no equilibrium in which the hiring order is other than $(1,2, \ldots K)$ or $(2,1, \ldots K)$.

Proof. Note that from the second round, $\alpha_{k}<1 / 2$ will always hold and firms will hire in the order of $\beta$ s. Therefore, we only need to show that firm $i>2$ hiring in the first round is not an equilibrium. Suppose instead that firms are hiring in the order $(i, 1,2, \ldots)$.

In that case, firm 1's profit when hiring in the second round is $\Pi_{1}^{2}=\alpha \beta_{1}\left(1-\beta_{i}\right)-\left[\alpha \beta_{1}\left(1-\beta_{i}\right)+(1-\alpha)\left(1-\beta_{1}\right) \beta_{i}\right] w_{2}=0.5 \beta_{1}\left(1-\beta_{i}\right)-0.5\left[\beta_{1}+\beta_{i}-2 \beta_{i} \beta_{1}\right] w_{2}$, and its profit when deviating to the first round is

$$
\Pi_{1}^{1}=\alpha \beta_{1}-\left[\alpha \beta_{1}+(1-\alpha)\left(1-\beta_{1}\right)\right] w_{1}=0.5 \beta_{1}-0.5 w_{1} .
$$

The condition that $\Pi_{1}^{2}=\Pi_{1}^{1}$ implies that $w_{1}=\beta_{1} \beta_{i}+\left[\beta_{1}+\beta_{i}-2 \beta_{i} \beta_{1}\right] w_{2}$.

For firm $i$, the profit it makes when hires in the first round is

$$
\Pi_{i}^{1}=\alpha \beta_{i}-\left[\alpha \beta_{i}+(1-\alpha)\left(1-\beta_{i}\right)\right] w_{1}=0.5 \beta_{i}-0.5 w_{1}
$$

Consider firm 2 that hires in the third round.

$$
\Pi_{2}^{3}=\alpha \beta_{2}\left(1-\beta_{i}\right)\left(1-\beta_{1}\right)-\left[\alpha \beta_{2}\left(1-\beta_{i}\right)\left(1-\beta_{1}\right)+(1-\alpha)\left(1-\beta_{2}\right) \beta_{1} \beta_{i}\right] w_{3},
$$

and its profit when deviating to the second round is

$$
\Pi_{2}^{2}=\alpha \beta_{2}\left(1-\beta_{i}\right)-\left[\alpha \beta_{2}\left(1-\beta_{i}\right)+(1-\alpha)\left(1-\beta_{2}\right) \beta_{i}\right] w_{2}
$$

If firm $i$ deviate to the third round, then its profit is

$$
\Pi_{i}^{3}=\alpha \beta_{i}\left(1-\beta_{2}\right)\left(1-\beta_{1}\right)-\left[\alpha \beta_{i}\left(1-\beta_{2}\right)\left(1-\beta_{1}\right)+(1-\alpha)\left(1-\beta_{i}\right) \beta_{1} \beta_{2}\right] w_{3},
$$




$$
\begin{aligned}
& \Pi_{i}^{3}-\Pi_{i}^{1}=\Pi_{i}^{3}-\Pi_{i}^{2}=\left[\Pi_{i}^{3}-\Pi_{2}^{3}\right]-\left[\Pi_{i}^{2}-\Pi_{2}^{2}\right] \\
& =0.5\left[\left(\beta_{i}-\beta_{2}\right)\left(1-\beta_{1}\right)+\left(\beta_{i}-\beta_{2}\right)\left(2 \beta_{1}-1\right) w_{3}\right] \\
& -0.5\left[\beta_{i}\left(1-\beta_{1}\right)-\beta_{2}\left(1-\beta_{i}\right)+\left[\left(2 \beta_{i}-1\right)\left(\beta_{1}-\beta_{2}\right)\right] w_{2}\right] \\
& =0.5\left[\beta_{2}\left(\beta_{1}-\beta_{i}\right)+\left(\beta_{i}-\beta_{2}\right)\left(2 \beta_{1}-1\right) w_{3}-\left(2 \beta_{i}-1\right)\left(\beta_{1}-\beta_{2}\right) w_{2}\right] \\
& >0.5\left[\beta_{2}\left(\beta_{1}-\beta_{i}\right)-\left(\beta_{2}-\beta_{i}\right)\left(2 \beta_{1}-1\right)-\left(2 \beta_{i}-1\right)\left(\beta_{1}-\beta_{2}\right)\right] \\
& =0.5\left[\left(\beta_{1}-\beta_{i}\right)\left(1-\beta_{2}\right)\right]>0
\end{aligned}
$$

This shows that no firm other than firm 2 could possibly hire in the first round. Thus, in any possible equilibrium, the order of hiring is either $2,1, \ldots K$ or $1,2, \ldots K$.

Lemma A6. When $\alpha=1 / 2$, in the case of $K>2$, the number of active firms $K$ is determined by the condition in (5). Hiring in the order of $(1,2, \ldots K)$ is always an equilibrium. In addition, under certain conditions, there is another equilibrium in which firms hire in the order $(2,1, \ldots K)$.

Proof. We consider cases with different $K$. To start, when $K=1$, obviously only firm 1 is active in the market. This happens under condition that $\frac{\alpha \beta_{1}}{\alpha \beta_{1}+(1-\alpha)\left(1-\beta_{1}\right)} \geq r>$ $\frac{\alpha\left(1-\beta_{1}\right) \beta_{2}}{\alpha\left(1-\beta_{1}\right) \beta_{2}+(1-\alpha) \beta_{1}\left(1-\beta_{2}\right)}$, which boils down to the conditions that $r \in\left(\frac{\left(1-\beta_{1}\right) \beta_{2}}{\beta_{1}+\beta_{2}-2 \beta_{1} \beta_{2}}, \beta_{1}\right]$ and $\left(\frac{\beta_{1}}{1-\beta_{1}}\right)^{2}<\frac{\beta_{2}}{1-\beta_{2}}$. Firm 1 pay a wage of $w_{1}=\max \left\{r, \beta_{2}\right\}$.

When $K=2$, both firm 1 and 2 are active in the market. Suppose firm 1 hires before firm 2 , then it must be true that

$$
\begin{gathered}
\frac{\left(1-\beta_{1}\right) \beta_{2}}{\left(1-\beta_{1}\right) \beta_{2}+\beta_{1}\left(1-\beta_{2}\right)} \geq r>\frac{\left(1-\beta_{1}\right)\left(1-\beta_{2}\right) \beta_{3}}{\left(1-\beta_{1}\right)\left(1-\beta_{2}\right) \beta_{3}+\beta_{1} \beta_{2}\left(1-\beta_{3}\right)} \\
w_{2}=\max \left\{r, \frac{\left(1-\beta_{1}\right) \beta_{3}}{\left(1-\beta_{1}\right) \beta_{3}+\beta_{1}\left(1-\beta_{3}\right)}\right\},
\end{gathered}
$$

firm 2 makes a profit of

$$
\Pi_{2}^{2}=0.5\left(1-\beta_{1}\right) \beta_{2}-0.5\left[\left(1-\beta_{1}\right) \beta_{2}+\beta_{1}\left(1-\beta_{2}\right)\right] w_{2}
$$

Note that $w_{1}$ is determined by the condition $\Pi_{2}^{1}=\Pi_{2}^{2}$, where $\Pi_{2}^{1}=0.5 \beta_{2}-0.5 w_{1}$. Thus

$$
\Pi_{1}^{1}=0.5 \beta_{1}-0.5 w_{1}
$$




$$
\Pi_{1}^{2}=0.5\left(1-\beta_{2}\right) \beta_{1}-0.5\left[\left(1-\beta_{2}\right) \beta_{1}+\beta_{2}\left(1-\beta_{1}\right)\right] w_{2},
$$

Note that $\Pi_{1}^{1}=\Pi_{1}^{2}$, thus firm 1 has no incentive to deviate.

Alternatively, suppose firm 2 hires before firm 1, then

$$
\begin{gathered}
\frac{\left(1-\beta_{2}\right) \beta_{1}}{\left(1-\beta_{2}\right) \beta_{1}+\beta_{2}\left(1-\beta_{1}\right)} \geq r>\frac{\left(1-\beta_{1}\right)\left(1-\beta_{2}\right) \beta_{3}}{\left(1-\beta_{1}\right)\left(1-\beta_{2}\right) \beta_{3}+\beta_{1} \beta_{2}\left(1-\beta_{3}\right)} \\
w_{2}=\max \left\{r, \frac{\left(1-\beta_{2}\right) \beta_{3}}{\left(1-\beta_{2}\right) \beta_{3}+\beta_{2}\left(1-\beta_{3}\right)}\right\},
\end{gathered}
$$

firm 1 makes a profit of

$$
\Pi_{1}^{2}=0.5\left(1-\beta_{2}\right) \beta_{1}-0.5\left[\left(1-\beta_{2}\right) \beta_{1}+\beta_{2}\left(1-\beta_{1}\right)\right] w_{2},
$$

Note that $w_{1}$ is determined by the condition $\Pi_{1}^{1}=\Pi_{1}^{2}$, where $\Pi_{1}^{1}=0.5 \beta_{1}-0.5 w_{1}$. Thus

$$
\begin{gathered}
\Pi_{2}^{1}=0.5 \beta_{2}-0.5 w_{1}, \\
\Pi_{2}^{2}=0.5\left(1-\beta_{1}\right) \beta_{2}-0.5\left[\left(1-\beta_{1}\right) \beta_{2}+\beta_{1}\left(1-\beta_{2}\right)\right] w_{2},
\end{gathered}
$$

Note that we need the condition $\Pi_{2}^{1} \geq 0$ to satisfy. Given that $\Pi_{2}^{1}=\Pi_{2}^{2}$, this condition is equivalent to:

$$
\beta_{1} \beta_{2}+\left(\beta_{1}+\beta_{2}-2 \beta_{1} \beta_{2}\right) \max \left\{r, \frac{\left(1-\beta_{2}\right) \beta_{3}}{\left(1-\beta_{2}\right) \beta_{3}+\beta_{2}\left(1-\beta_{3}\right)}\right\} \leq \beta_{2} .
$$

When $K>2$, it is obvious that number of active firms $K$ should be determined by condition (5), following the same logic as in Proposition 5. Also, hiring order $(1,2, \ldots K)$ is an equilibrium follows the same steps as in the proof of Proposition 5, with only very minor modifications. Thus, we only need to lay out the conditions under which hiring order $(2,1, \ldots K)$ is also an equilibrium.

First, note that from the second round $\alpha_{k}<1 / 2$, thus hiring must happen in the order of $\beta \mathrm{s}$ in any equilibrium. We only need to show that: 1) no firms other than firm 2 has the incentive to deviate to hire in the first round, and 2) firm 2 has no incentive to deviate to hire in later rounds.

Clearly, firm 1 has no incentive to deviate to the first round since $\Pi_{1}^{2}=\Pi_{1}^{1}$. To see that firm $k>2$, who hires in the $k$-th round, has no incentive to hire in the first round, 
note that $\Pi_{k}^{1}=0.5 \beta_{k}-0.5 w_{1}$, while $\Pi_{k}^{2}=0.5\left(1-\beta_{2}\right) \beta_{k}-0.5\left[\left(1-\beta_{2}\right) \beta_{k}+\beta_{2}\left(1-\beta_{k}\right)\right] w_{2}$. We have

$$
\Pi_{k}^{2}-\Pi_{k}^{1}=\left[\Pi_{k}^{2}-\Pi_{1}^{2}\right]-\left[\Pi_{k}^{1}-\Pi_{1}^{1}\right]=0.5\left(\beta_{1}-\beta_{k}\right)\left[\beta_{2}-\left(2 \beta_{2}-1\right) w_{2}\right]>0,
$$

where the last inequality follows because $\beta_{2}<1$ and $w_{2}<1$.

Following Proposition 5, we know that $\Pi_{k}^{k}>\Pi_{k}^{2}$, thus $\Pi_{k}^{k}>\Pi_{k}^{1}$ and firm $k$ has no incentive to deviate to the first round.

We then examine the incentives of firm 2 to hire in later rounds. First, as $\Pi_{2}^{1}=$ $\Pi_{2}^{2}=\left[\Pi_{2}^{2}-\Pi_{1}^{2}\right]-\left[\Pi_{2}^{1}-\Pi_{1}^{1}\right]=0$, firm 2 has no incentive to deviate to the second round. Second, note that Proposition 5 also ensures that $\Pi_{2}^{k}>\Pi_{2}^{k+1}$ for $k \geq 3$. Therefore, we only need to consider the possibility that firm 2 might deviate to the third round.

$$
\begin{aligned}
& \Pi_{2}^{3}-\Pi_{2}^{1}=\Pi_{2}^{3}-\Pi_{2}^{2}=\left[\Pi_{2}^{3}-\Pi_{3}^{3}\right]-\left[\Pi_{2}^{2}-\Pi_{3}^{2}\right] \\
& =0.5\left[\left(\beta_{2}-\beta_{3}\right)\left(1-\beta_{1}\right)+\left(\beta_{2}-\beta_{3}\right)\left(2 \beta_{1}-1\right) w_{3}\right] \\
& -0.5\left[\beta_{2}\left(1-\beta_{1}\right)-\beta_{3}\left(1-\beta_{2}\right)+\left[\left(2 \beta_{3}-1\right)\left(\beta_{1}-\beta_{3}\right)\right] w_{2}\right] \\
& =0.5\left[\beta_{3}\left(\beta_{1}-\beta_{2}\right)+\left(\beta_{2}-\beta_{3}\right)\left(2 \beta_{1}-1\right) w_{3}-\left(2 \beta_{2}-1\right)\left(\beta_{1}-\beta_{3}\right) w_{2}\right]
\end{aligned}
$$

Thus as long as $\Pi_{2}^{3} \leq \Pi_{2}^{1}$, the hiring order of $(2,1, \ldots K)$ is an equilibrium. Because $\Pi_{3}^{3}=\Pi_{3}^{2}$ implies $w_{2}=\frac{\beta_{1} \beta_{3}\left(1-\beta_{2}\right)+\left[\left(1-\beta_{1}\right)\left(1-\beta_{2}\right) \beta_{3}+\beta_{1} \beta_{2}\left(1-\beta_{3}\right)\right] w_{3}}{\beta_{2}+\beta_{3}-2 \beta_{2} \beta_{3}}$. This implies the following condition needs to hold.

$$
\frac{\beta_{3}\left(\beta_{1}-\beta_{2}\right)+\left(\beta_{2}-\beta_{3}\right)\left(2 \beta_{1}-1\right) w_{3}}{\left(2 \beta_{2}-1\right)\left(\beta_{1}-\beta_{3}\right)} \leq \frac{\beta_{1} \beta_{3}\left(1-\beta_{2}\right)+\left[\left(1-\beta_{1}\right)\left(1-\beta_{2}\right) \beta_{3}+\beta_{1} \beta_{2}\left(1-\beta_{3}\right)\right] w_{3}}{\beta_{2}+\beta_{3}-2 \beta_{2} \beta_{3}} .
$$

Note that $w_{3}$ is determined by all the $\beta$ s and $K$.

\section{Appendix B}

Here we consider a simultaneous wage posting model. Free entry implies that firms make zero profit in equilibrium. There is a continuum of workers of two types, $\alpha$ proportion of high type and $1-\alpha$ proportion of low type. Firms make simultaneous job offers to workers they intend to hire at offered wages. Upon receiving offers, 
workers decide which firm's offer to accept. Workers always take the highest wage offer, provided that it is greater or equal to the reservation wage $r$. Production starts after the firm-worker matching process is completed.

First, note that no two firms can offer the same wage. The intuition is similar to that in Varian (1980) and Burdett and Mortensen (1998). Suppose both firm A and $\mathrm{B}$ offer the same wage $w$. Let the measures of high type and low type workers who receive offer from firm $\mathrm{A}$, but no other offer higher than $w$, be $n_{A}$ and $m_{A}$, respectively. Among those workers, $n_{A} \beta$ high type workers and $m_{A}(1-\beta)$ low type workers will also receive offer from firm $B$. In equilibrium, only half of those workers who receive offers from both firms will choose to accept firm A's offer. Thus, the average productivities of workers firm A hires at equilibrium is $\frac{n_{A}(1-\beta / 2)}{n_{A}(1-\beta / 2)+m_{A}[1-(1-\beta) / 2]}$. However, firm A could deviate by offering $w+\epsilon$ and get all workers that also receive an offer from firm B. The resulting average productivity of workers hired by firm A will be $\frac{n_{A}}{n_{A}+m_{A}}$, which is strictly higher.

Second, we show that no pure strategy equilibrium exist. Because no two firms offer the same wages and workers only accept the highest offer received, the equilibrium can be analyzed as if the game is sequential, i.e., firms who post higher wages hire first. Let the firm who offer the highest wage $\left(w_{1}\right)$ and the second highest wage $\left(w_{2}\right)$ be denoted as firm 1 and firm 2, respectively. Clearly, firm 1 will send offer to those workers it labels as " $h$ " (or a random subset), and hire workers with average productivity $H_{1}=\frac{\alpha \beta}{\alpha \beta+(1-\alpha)(1-\beta)}$. The zero profit condition guarantees that $w_{1}=H_{1}$. Suppose firm 1 hires $\delta(0<\delta \leq 1)$ proportion of workers it labels as " $h$ ", then average productivity of workers hired by firm 2 will be $H_{2}=\frac{\alpha(1-\delta \beta) \beta}{\alpha(1-\delta \beta) \beta+(1-\alpha)[1-\delta(1-\beta)](1-\beta)}$. Note that $H_{2}<H_{1}$ and $H_{2}=w_{2}$. However, in this case firm 1 could deviate by offering only $w_{2}+\epsilon$ and still be able to hire the same workers, thus make a positive profit.

We then consider the possibility of mixed strategy equilibrium. Note that the intuition of no two firms offer the same wage still holds, thus there should be no point mass in the support of firms' wage offers. Even though firms randomly choose one wage to post each time, in any realization, we could still rank the wage offers for all active firms from the highest to the lowest $\left(w_{1}>\ldots>w_{k}>\ldots>w_{K}\right)$. The 
hiring process is still characterized by cherry picking as described in Proposition 1, and the average productivities of workers hired by those firms will be decreasing $\left(H_{1}>\ldots>H_{k}>\ldots>H_{K}\right)$. Thus in the equilibrium there still exists wage dispersion and size-wage premium (under Assumption 1). The only difference is that $w_{k}=H_{k}$ no longer holds. Rather, the expected profit (across all realizations) of all firms should be zero.

Finally, we give a simple example of mixed strategy equilibrium (similar to Varian 1980). Let Assumption 1 holds, and $H_{1}>H_{2}=r>H_{3}$, where $H_{k}=\frac{\alpha \beta(1-\beta)^{k-1}}{\alpha \beta(1-\beta)^{k-1}+(1-\alpha) \beta^{k-1}(1-\beta)}$ for $k=1,2,3$. Note first that at most two firms can be active in equilibrium, as the firm offering the third largest wage can only hire workers with average productivities of $\mathrm{H}_{3}$, which is lower than the reservation wage.

We only consider symmetric mixed strategy equilibrium, in which both active firms randomly choose a wage to post from a $\operatorname{CDF} F(x)=\operatorname{prob}(w<x)$ in the $\operatorname{support}[\underline{w}, \bar{w}]$.

It is clear that $\bar{w}=H_{1}$. Note that offering a wage greater than $H_{1}$ is a strictly dominated strategy. Also, if $\bar{w}<H_{1}$, then an inactive firm could deviate to offer something between $\bar{w}$ and $H_{1}$, thus make a positive profit.

Similarly, $\underline{w}=r$. Note $\underline{w}>r$ is also a strictly dominated strategy, as both active firms can make more profit by lowering $\underline{w}$. But $\underline{w}$ cannot be lower than $r$ as well, at it is the reservation wage.

Since there are no point masses in the equilibrium density, the cumulative distribution function will be continuous on $\left[r, H_{1}\right]$. Given $F(w)$, the expected profit of firm $i$ equals

$$
\int_{r}^{H_{1}}\left\{\pi_{h} F(w)+\pi_{l}(1-F(w))\right\} d F(w),
$$

where $\pi_{h}=\alpha \beta-(\alpha \beta+(1-\alpha)(1-\beta)) w$ is the total profit if firm i post the highest wage, $\pi_{l}=(\alpha-w)(1-\beta) \beta$ is total profit if firm i post the second highest wage.

All wages that are offered with positive density must yield the same expected profit zero for the firm. Otherwise, the firm could profitably increase the frequency with which the more profitable wage were posted. This condition indicates

$$
\pi_{h} F(w)+\pi_{l}(1-F(w)=0 .
$$


Simplification gives

$$
F(w)=\frac{(w-\alpha)(1-\beta) \beta}{\alpha \beta^{2}-\left(\alpha \beta^{2}+(1-\alpha)(1-\beta)^{2}\right) w} .
$$

Note that $F(r)=0$, and $F\left(H_{1}\right)=1$.

In equilibrium, both firms play mixed strategy, offering $w$ following the distribution $F(w)$. Alll other firms remain inactive, and have no incentive to be active by playing a mixed strategy based on $F(w)$, as the expected profit will be negative. Since $F(\cdot)$ is a continuous distribution, the case of a tie can be ignored without loss of generality. In any equilibrium outcome, the two firms will offer different wages. The firm who offers the highest wage will hire more workers, thus there exists wage dispersion and size-wage premium in the simultaneous game. 